\title{
Multi-gene incongruence consistent with hybridisation in Cladocopium (Symbiodiniaceae), an ecologically important genus of coral reef symbionts
}

\author{
Joshua I Brian ${ }^{1}$, Simon K Davy ${ }^{\text {Corresp., }}{ }^{1}$, Shaun Peter Wilkinson ${ }^{1}$ \\ ${ }^{1}$ School of Biological Sciences, Victoria University of Wellington, Wellington, New Zealand \\ Corresponding Author: Simon K Davy \\ Email address: simon.davy@vuw.ac.nz
}

Coral reefs rely on their intracellular dinoflagellate symbionts (family Symbiodiniaceae) for nutritional provision in nutrient-poor waters, yet this association is threatened by thermally stressful conditions. Despite this, the evolutionary potential of these symbionts remains poorly characterised. In this study, we tested the potential for divergent Symbiodiniaceae types to sexually reproduce (i.e. hybridise) within Cladocopium, the most ecologically prevalent genus in this family. With sequence data from three organelles (cob gene, mitochondria; $\mathrm{psbA}^{\mathrm{ncr}}$ region, chloroplast; and ITS2 region, nucleus), we utilised the Incongruence Length Difference test, Approximately Unbiased test, tree hybridisation analyses and visual inspection of raw data in stepwise fashion to highlight incongruences between organelles, and thus provide evidence of reticulate evolution. Using this approach, we identified three putative hybrid Cladocopium samples among the 158 analysed, at two of the seven sites sampled. These samples were identified as the common Cladocopium types $\mathrm{C} 40$ or $\mathrm{C} 1$ with respect to the mitochondria and chloroplasts, but the rarer types $\mathrm{C} 3 z, \mathrm{C} 3 \mathrm{u}$ and $\mathrm{C} 1 \#$ with respect to their nuclear identity. These five Cladocopium types have previously been confirmed as evolutionarily distinct and were also recovered in non-incongruent samples multiple times, which is strongly suggestive that they sexually reproduced to produce the incongruent samples. A concomitant inspection of Next Generation Sequencing data for these samples suggests that other plausible explanations, such as incomplete lineage sorting or the presence of codominance, are much less likely. The approach taken in this study allows incongruences between gene regions to be identified with confidence, and brings new light to the evolutionary potential within Symbiodiniaceae. 
1 Multi-gene incongruence consistent with hybridisation in Cladocopium (Symbiodiniaceae),

2 an ecologically important genus of coral reef symbionts

3

\section{Authors}

5 Joshua I. Brian ${ }^{1 \dagger}$, Simon K. Davy ${ }^{1}$, Shaun Peter Wilkinson ${ }^{1}$

6

7 Author Affiliations

$8{ }^{1}$ School of Biological Sciences, Victoria University of Wellington, Kelburn Parade, Wellington 9 6012, New Zealand.

$10 \dagger$ Current address: Aquatic Ecology Group, Department of Zoology, University of Cambridge,

11 Downing Street, Cambridge CB2 3EJ, United Kingdom

\section{Corresponding Author}

14 Simon K. Davy

15 email: simon.davy@vuw.ac.nz

16 phone: +6444635339

17 fax: +6444635331 
22 Abstract

23

24 Coral reefs rely on their intracellular dinoflagellate symbionts (family Symbiodiniaceae) for 25 nutritional provision in nutrient-poor waters, yet this association is threatened by thermally stressful conditions. Despite this, the evolutionary potential of these symbionts remains poorly characterised. In this study, we tested the potential for divergent Symbiodiniaceae types to sexually reproduce (i.e. hybridise) within Cladocopium, the most ecologically prevalent genus in this family. With sequence data from three organelles (cob gene, mitochondria; $\mathrm{psbA}^{\mathrm{ncr}}$ region, chloroplast; and ITS2 region, nucleus), we utilised the Incongruence Length Difference test, Approximately Unbiased test, tree hybridisation analyses and visual inspection of raw data in stepwise fashion to highlight incongruences between organelles, and thus provide evidence of reticulate evolution. Using this approach, we identified three putative hybrid Cladocopium samples among the 158 analysed, at two of the seven sites sampled. These samples were identified as the common Cladocopium types $\mathrm{C} 40$ or $\mathrm{C} 1$ with respect to the mitochondria and chloroplasts, but the rarer types $\mathrm{C} 3 \mathrm{z}, \mathrm{C} 3 \mathrm{u}$ and $\mathrm{C} 1 \#$ with respect to their nuclear identity. These five Cladocopium types have previously been confirmed as evolutionarily distinct and were also recovered in nonincongruent samples multiple times, which is strongly suggestive that they sexually reproduced to produce the incongruent samples. A concomitant inspection of Next Generation Sequencing data for these samples suggests that other plausible explanations, such as incomplete lineage sorting or the presence of co-dominance, are much less likely. The approach taken in this study allows incongruences between gene regions to be identified with confidence, and brings new light to the evolutionary potential within Symbiodiniaceae. 
46

47

\section{Introduction}

Coral reefs are a highly diverse and important ecosystem, yet are significantly threatened by anthropogenically-driven climate change (Hughes et al. 2017). In order for coral reefs to survive the stresses of a changing climate, genetic adaptation over rapid evolutionary timescales has to occur. Adaptation in the coral itself may go some way to provisioning for the environmentally challenging conditions predicted to come (Rodriguez et al. 2009). However, given that the response of corals to environmental conditions is inextricably linked to the diversity and performance of their intracellular symbionts (dinoflagellates of the family Symbiodiniaceae, LaJeunesse et al. 2018) increasing attention is being focused on the evolutionary potential within this family.

(2)

7 Coral symbionts have been thought to be exclusively asexual in hospite (Trench 1997; LaJeunesse 2005), thanks to their isolated position sequestered inside host cells, and the hypothesis that endosymbiotic sex would encourage exploitation of the host (Law and Lewis 1983). However, previous work in other taxa has shown that intracellular symbionts can sexually reproduce (Chesnick and Cox 1987). In general, it is thought that many such organisms may have cryptic sexual cycles that have previously been unappreciated, in addition to the production of clonal populations via asexual reproduction (Heitman 2010). Now, there is significant evidence that Symbiodiniaceae also displays a mixed reproductive strategy, with periods of asexuality interspersed with occasional to frequent sex (Thornhill et al. 2017). While it has never been explicitly observed, there are distinct and observable traces of sex in their genomes (e.g. Baillie et al. 2000; LaJeunesse 2001; Santos and Coffroth 2003; Santos et al. 2004; Pettay et al. 2011; Baums 
68 et al. 2014; Chi et al. 2014; LaJeunesse et al. 2014; Thornhill et al. 2014; Levin et al. 2016).

69 However, these studies have been largely focused on a micro-scale, population level (i.e.

70 intraspecific sex). By contrast, sex between diverse symbiont lineages ('hybridisation') has

71 received little attention in the literature (but see Wilkinson et al. 2015). Given the highly thermally

72 stressful conditions predicted by the end of the century (Kirtman et al. 2013), the mechanism of

73 hybridisation could potentially have significant and vital adaptive value. By mixing diverse pools

74 of genetic material, hybridisation can allow for rapid adaptation, facilitating macro-evolutionary

75 jumps (Willis et al. 2006; Dittrich-Reed and Fitzpatrick 2013). Introgressive hybridisation, where

76 the F1 hybrids subsequently mate with one or both parent populations, can transfer a large quantity

77 of genetic material between the two parent lineages in the space of a few generations. In addition,

78 hybridisation can also produce offspring with elevated fitness ('hybrid vigour'), which can even

79 outcompete the parent species (Ellstrand and Hoffman 1990; Rhymer and Simberloff 1996).

80 Importantly, instances of hybridisation have also been shown to increase in taxing conditions

81 (Rhymer and Simberloff 1996; Moran and Alexander 2014). Therefore, the possibility of

82 hybridisation in coral symbionts raises the potential for adaptation at the required pace and scale

83 for survival.

Research on taxa with similar life-histories suggests that hybridisation is plausible. Hybridisation has previously been reported in a range of dinoflagellate genera, including Dinophysis, Protoperidinium, Preperidinium and Diplopsalis (Edvardsen et al. 2003; Gribble and Anderson 2007; Hart et al. 2007). There is also evidence from plant-fungi relationships that endosymbionts can successfully hybridise. In particular, the endophytes Epichloë spp. are pathogenic or 
91 mechanism for diversification in this genus, and has been reported to occur inside the grasses

92 Lolium perenne (Schardl et al. 1994), Festuca arundinacea (Tsai et al. 1994), Bromus laevipes

93 (Charlton et al. 2014) and Poa alsodes (Shymanovich et al. 2017). In several instances, multiple

94 cases of hybridisation have been recorded, and evidence put forward that those hybrids are fitter

95 than non-hybrids (Schardl et al. 1994; Moon et al. 2004). While Symbiodiniaceae in hospite are

96 generally sequestered inside host cells (Davy et al. 2012), the extensive presence of background

97 symbiont populations inside hosts (Santos et al. 2001; Kemp et al. 2015), the observation that

98 corals themselves hybridise (Willis et al. 2006; Combosch and Vollmer 2015), and the existence

99 of a free-living state (Coffroth et al. 2006; Nitschke et al. 2016) mean that it is highly possible that

100 at some point diverse symbiont communities may interact, with the possibility for sexual

101 reproduction.

102

103 The evolutionary potential of hybridisation has not been targeted within Symbiodiniaceae.

104 However, several indirect observations are suggestive of its occurrence, all within Cladocopium,

105 the most prevalent genus. LaJeunesse et al. (2003) reported an ITS2 sequence variant they called

$106 \mathrm{Clc}$ and treated as an intragenomic variant, as it was only observed in DGGE profiles associated

107 with type $\mathrm{C} 1$. However, it was then discovered to be an independent type and called C45

108 (LaJeunesse 2005). Therefore, the additive DGGE pattern shown in LaJeunesse et al. (2003) could

109 have in fact resulted from the hybridisation of C1 and C45. LaJeunesse (2005) also defined type

$110 \mathrm{C} 3 \mathrm{~m}$ using the ITS2 region, which has co-dominant characteristics of both $\mathrm{C} 1$ and $\mathrm{C} 3$, a pattern

111 attributed to either sexual recombination or homoplasy. A similar scenario was also recorded in

112 symbiont type C3h, an apparent intermediary between C3 and C21 (LaJeunesse et al. 2004). This

113 time, the pattern was hypothesised to be due to incomplete lineage sorting or sexual recombination 
114 between the two different types. Indeed, given the unambiguous existence of 'pure' C3 and C21

115 in the samples, sexual recombination is a credible explanation. Finally, Wilkinson et al. (2015)

116 reported two symbiont types but three distinct symbiont populations inside a single Pocillopora

117 colony: C100 symbionts, C109 symbionts, and symbionts having co-dominant C100 and C109

118 repeats in the same cell. Again, the extensive presence of the two 'pure' populations means

119 incomplete lineage sorting is a less parsimonious explanation than hybridisation. However, it 120 cannot be completely eliminated as a possibility. In addition, this study took place at Lord Howe

121 Island, the world's southern-most coral reef, and therefore may not be widely applicable across

122 less marginal, low-latitude sites.

124 Hence, there is a body of indirect evidence for sexual recombination between diverse symbiont 125 types (hybridisation sensu lato), and this warrants further study. The current study aimed to gather 126 further defendable evidence as to whether hybridisation occurs in coral symbionts. Because it is 127 very difficult to observe hybridisation directly, it is generally inferred through genetic signals. One 128 of the most common of these is incongruence between gene regions. Because nuclear genes are 129 typically inherited biparentally, while organelle genes are inherited uniparentally, sexual reproduction between different species will result in organelle genes resembling one parent only, while the nuclear genome will have clear traces of both parents (Rieseberg et al. 1996). In extreme cases, repeated backcrosses with a parent type can result in organelle capture, where novel, discordant nuclear-organellar combinations are observed (Folk et al. 2017). Following a hybridisation event, selection can also act to produce incongruence between gene regions: there may be elevated (or reduced) fitness of certain nuclear-cytoplasmic combinations, or selection 136 pressure may be different for nuclear and cytoplasmic genomes (e.g. a greater selection pressure 
137 acting on nuclear genes) (Rieseberg et al. 1996). Therefore, identifying incongruence between 138 gene regions is a common method for assessing potential hybridisation (Planet et al. 2006; 139 Govindarajulu et al. 2015), and was utilised in the current study.

141 The chosen location for this study, Atauro Island and the north coast of Timor, is in the Coral 142 Triangle and therefore widely applicable to other important reef systems. The hypothesis tested 143 was that hybridisation between distinct Cladocopium genotypes has occurred at these sites, as 144 evidenced by gene regions in separate organelles ( $c o b$, mitochondria; ITS2, nucleus; psbA ${ }^{\text {ncr }}$, 145 chloroplast) having experienced different evolutionary histories. Defendable evidence of 146 hybridisation would be a significant step towards understanding the evolution of Symbiodiniaceae 147 and potential coral reef persistence in the future.

Materials and methods

Data acquisition

152

153

This study represents a novel analysis of the data presented in Brian et al. (2019). Briefly, 43 coral genera were sampled from four sites at Atauro Island: BBR (Beloi Barrier Reef); BHB (Beloi Harbour); BLS (Beloi Lagoon South); and BSP (Beloi Saddlepatch) (for a complete list of genera see Table S1 of Brian et al. 2019). In addition, three sites were sampled on the northern coast of Timor: HEW (Hera West); LIE (Lamsana Inlet East); and LIW (Lamsana Inlet West). In total, 650 samples were collected from the seven sites. The corals in this study were sampled with the permission of the Ministerio da Agricultura e Pescas (permit number LNC-PC0012.VI.16). 
160 Symbiont DNA was extracted using a guanidinium protocol, and amplification via PCR was

161 carried out for the $c o b$, ITS2 and $\mathrm{psbA}^{\mathrm{ncr}}$ regions of the symbiont DNA. For full details of PCR

162 reactions and conditions, see the Supplementary Material. The cob amplification utilised either

163 Dinocob1F/Dinocob1R (Zhang et al. 2005) or Cob_f1/Cob_r1 (Pochon et al. 2012) primers, while

164 the $\mathrm{psbA}^{\mathrm{ncr}}$ amplification utilised the primers 7.4-Forw/7.8-Rev (Moore et al. 2003). Following

165 purification with MagNA solution (Rohland and Reich 2012), the $c o b$ and psbA $^{\text {ncr }}$ were sequenced

166 in the forward direction with traditional Sanger sequencing (Macrogen Inc., Seoul, South Korea).

167 In contrast, the ITS2 region was amplified via Next Generation Sequencing (NGS). Samples

168 underwent an initial amplification with the primers ITSD (Pochon et al. 2001) and ITS2Rev2 (Stat

169 et al. 2009), with Illumina adapters attached. Amplicons were purified using MagNA solution, and

170 unique forward/reverse index primers (IDT) were annealed to the ends of each amplification using

171 a second short PCR run of 8 cycles. Amplifications were quantified and checked for quality using

172 qPCR (Applied Biosystems StepOne instrument), with the primers ITSD/ITS2Rev2. All samples

173 were pooled, with different volumes of each sample added to achieve an equal concentration (final

174 concentration of pooled library: 4 nM DNA). The pooled library was sequenced on a single lane

175 of the Illumina MiSeq platform by the Centre for Genomics and Proteomics, University of

176 Auckland, New Zealand. As the incongruence tests utilised (see below) require a single sequence

177 per sample, the most dominant ITS2 sequence from the NGS in each sample was extracted (an

178 'ASV' in Brian et al. 2019). While this was necessary for analysis, it could lead to interpretational

179 issues (see Discussion). Only samples that had successful sequences for all three gene regions were

180 chosen, as the tests require exactly the same taxa lists for each tree or partition. Further, only

181 samples that could be placed in an unambiguous alignment were used, which eliminated several 
182 samples with highly divergent psbA $^{\text {ncr }}$ sequences. This left between 18 and 28 samples per site $(\bar{x}$ $183=22.6$ ), with a total of 158 samples used.

184

Incongruence tests

186

187

Ideally, a statistical test would be able to test the null hypothesis 'Dataset $\mathrm{X}$ and Dataset $\mathrm{Y}$ are not 188 incongruent', against an alternate hypothesis 'Dataset $\mathrm{X}$ and Dataset $\mathrm{Y}$ are incongruent.' A test with this explicit hypothesis does not exist for phylogenetic data, so other tests with slightly different hypotheses have been frequently employed as an approximation. Two of these tests were utilised in this study.

The Incongruence Length Difference (ILD) test (Farris et al. 1994) uses the criterion of maximum parsimony, and compares two data partitions (nucleotide alignments) $\mathrm{X}$ and $\mathrm{Y}$, of arbitrary length. The null hypothesis is that the defined partitions $(\mathrm{X}, \mathrm{Y})$ are no more parsimonious (in terms of making a phylogeny) than random partitions generated from a combination of $\mathrm{X}$ and $\mathrm{Y}$, while the alternate hypothesis is that the defined partitions are significantly more parsimonious than random partitions. Functionally, this can be used to test if two datasets have undergone separate evolutionary histories (Planet 2006). The implication is that if $\mathrm{X}$ and $\mathrm{Y}$ are indeed more parsimonious, they encode contrary evolutionary information that is lost when randomised.

The Shimodaira-Hasegawa (SH) test (Shimodaira and Hasegawa 1999) is an explicit tree-based test using the criterion of maximum likelihood (ML), comparing how well phylogenetic trees explain alignment data. The null hypothesis is that all tested trees are equally good explanations 
205 of the data, while the alternate is that some or all tested trees are not equally good explanations of

206 the data. In practice, this test identifies the best tree for a given dataset (i.e. a multiple sequence

207 alignment), and then presents output as to whether other candidate trees are statistically distinct

208 from that best tree. The output hence appears as pairwise comparisons between two trees. This

209 procedure can be used to test for incongruence in datasets $\mathrm{X}$ and $\mathrm{Y}$, using trees $\mathrm{T}_{\mathrm{X}}$ and $\mathrm{T}_{\mathrm{Y}}$ made

210 from those datasets. If $\mathrm{T}_{\mathrm{X}}$ and $\mathrm{T}_{\mathrm{Y}}$ are equally likely for all or most characters in $\mathrm{X}$ and in $\mathrm{Y}$ (tested

211 in two separate tests), the test will find a p-value $>0.05$, and it can be concluded that $\mathrm{X}$ and $\mathrm{Y}$ are

212 not incongruent, as their trees do an equally good job of explaining each other's data. If they are

213 incongruent, it is expected that $\mathrm{T}_{\mathrm{X}}$ will be significantly better than $\mathrm{T}_{\mathrm{Y}}$ when considering dataset $\mathrm{X}$,

214 and vice versa for $\mathrm{T}_{\mathrm{Y}}$ and $\mathrm{Y}$. The Approximately Unbiased (AU) test was developed by Shimodaira

215 (2002) as a derivation of the SH test, and generally finds more accurate results when there are

216 many candidate trees, or some trees are particularly unlikely (Shimodaira 2002; Strimmer and

217 Rambaut 2002); the AU test was hence utilised for testing procedures.

218

219 To identify incongruence, these two tests (ILD, AU) in addition to other analyses described below

220 were conducted in stepwise fashion (Fig. 1).

221

222 Data assembly

223

224 Alignments were created and manually edited in Geneious v8.0.5 (Biomatters), using the built-in

225 Geneious alignment algorithm with all default settings (gap open penalty $=12$, extension $=3$ ).

226 Each site (BBR, BHB, BLS, BSP, HEW, LIE, LIW) had a separate alignment for each gene region

$227\left(c o b, \mathrm{psbA}^{\mathrm{ncr}}, \mathrm{ITS} 2\right)$, leading to 21 alignments. Additional holistic datasets for each gene region 
228 were created for Atauro Island (92 samples) and Timor (66 samples), to facilitate broad-scale 229 island comparisons. All alignments had 787, 369 and 531 columns for the cob, ITS2 and psbA ${ }^{\text {ncr }}$ 230 regions, respectively. In total, 27 separate datasets were assembled (3 marker regions x ( 7 sites + 2312 main islands)). Datasets can be accessed online at 232 github.com/brianjosh/Cladocopium_alignments. Durusdinium glynnii (D1) was used as the 233 outgroup for these analyses (GenBank Accession Numbers: KY131780 (cob); JN558075 (ITS2); 234 MH329571 ( psbA $\left.^{\text {ncr }}\right)$ ). Gaps were coded as a fifth character state. All analyses described below 235 used the program PAUP* 4.0a161 (Swofford 2002) unless otherwise specified. Note that in 236 PAUP*, the ILD test is called the partition homogeneity test.

Incongruence Length Difference (ILD) tests

The three gene regions were concatenated for each site, with each region then treated as a separate partition (cob: 1-787; ITS2: 788-1156; psbA ncr 1157-1687; total of 1687 columns). This was carried out for each site, plus for Atauro Island samples and Timor samples as above (total of nine different concatenations). The individual site analyses were originally carried out with 100 replications, using a MaxTrees value (number of trees stored at any one time) of 1000. For results that had $\mathrm{p}$-values $<0.2$, a more thorough confirmatory analysis was run with 1000 replicates and a MaxTrees value of 10000 . In all cases, the p-values between the two sets of tests differed by $<0.015$, and therefore the tests with original p-values $>0.2$ would be extremely unlikely to change the result if the more extensive tests had been run on them. All other settings used for the tests were the PAUP* defaults. Conclusions were drawn at $\alpha=0.05$. The null hypothesis was that there was no incongruence between the three partitions. 
Approximately Unbiased (AU) tests

253

254 Maximum likelihood trees were generated for all gene regions by individual site (all possible combinations of $\left\{c o b, \mathrm{psbA}^{\mathrm{ncr}}, \mathrm{ITS} 2\right\}$ and $\{\mathrm{BBR}, \mathrm{BHB}, \mathrm{BLS}, \mathrm{BSP}, \mathrm{HEW}, \mathrm{LIE}, \mathrm{LIW}\}$ i.e. 21 different trees). Trees were also made for each gene region for Atauro Island and Timor datasets

257 (i.e. six trees). The appropriate evolutionary model was determined for each of the 27 datasets individually by first making a neighbour-joining tree using a Jukes-Cantor distance measure and running the automodel command. The appropriate evolutionary model for each dataset was then employed when making the maximum likelihood trees (Table S1). A basic heuristic search was run to generate a base tree or trees, which was then bootstrapped. All bootstrapping procedures used a heuristic search with random sequence addition and had unlimited MaxTrees; all other settings were the PAUP* defaults. cob datasets had 1000 bootstrap replicates, while the ITS2 and psbA $^{\text {ncr }}$ datasets had 100 replicates. In addition, for the $\operatorname{psbA}^{\text {ncr }}$ datasets, the number of addition sequence replicates was set to 2 (versus the default of 10), to limit computational burden. The search option for all three gene regions. Nodes with $<50 \%$ bootstrap support were collapsed into polytomies. This procedure yielded 27 maximum likelihood trees, one for each gene region for each of the nine datasets.

A set of 100 random trees was also generated for each dataset, using the generate random

272 command employing an equiprobable model. These additional trees are necessary to gain an accurate p-value. In theory, every single possible tree topology of the data should be present, to 
274 ensure that the 'true' maximum likelihood tree is available to be chosen by the test, and to allow

275 calculation of the null distribution for the test statistic (Goldman et al. 2000; Planet 2006).

276 However, given that the number of possible topologies increases exponentially with the addition

277 of taxa, this criterion is functionally impossible to meet for most modern studies. As such, a

278 random subset of all possible topologies is chosen instead (e.g. Robinson et al. 2005).

Because the AU test assesses whether competing trees are equally likely hypotheses of the data,

281

282

283

284

285

286

287

288

289

290

291

292

293

294

295 the choice of dataset will affect the conclusions of the test: it may be expected that for dataset X, tree $T_{X}$ made from that dataset may be statistically better than another tree $T_{Y}$, even if they do not inherently disagree. This would not be evidence for incongruence, just the test behaving in its originally intended manner. Because of this, for each site, reciprocal AU tests were run. For example, for site BBR, the $c o b \mathrm{BBR}$ alignment was initially used as the dataset for the test, and all three trees (from the $c o b$ BBR, ITS2 BBR and psbA ncr BBR alignments) were compared with the AU test, to see: (a) which of the trees explained the dataset best, and (b) whether the other trees were significantly worse than the best tree at explaining the dataset. This was then repeated using the ITS2 BBR and $\mathrm{psbA}^{\mathrm{ncr}} \mathrm{BBR}$ alignments as the dataset in question, to compare the same three trees. 10000 RELL (resampling estimated log-likelihood, Kishino et al. 1990) bootstrap replicates were used for calculation of p-values. Because there were six pairwise comparisons carried out for each site (best tree $v s$. other two trees for $c o b, \mathrm{psbA}^{\mathrm{ncr}}$ and ITS2 regions), a within-site Bonferroni correction was applied $(\alpha=0.0085)$. The null hypothesis was that the two trees being compared explained the sequence alignment equally well. The gene regions were considered incongruent if there was reciprocal incongruence; for example, if the ITS2 tree was significantly worse than the 
$296 c o b$ tree at explaining the $c o b$ dataset and the $c o b$ tree was significantly worse than the ITS2 tree

297 at explaining the ITS2 dataset.

298

299 Post hoc analyses

300

301 Based on the original analyses, several datasets displayed consistent evidence of incongruence (see

302 Results). To verify these results, further ILD tests were executed, using only two gene regions at

303 a time (e.g. for a single site, the following concatenations were assembled and tested: cob vs. ITS2;

$304 c o b$ vs. psbA ${ }^{\text {ncr. }}$ ITS2 vs. psbA $^{\text {ncr }}$ ). As there were three tests per site, conclusions were drawn at a

305 Bonferroni-corrected $\alpha=0.017$. This allowed the location of incongruence to be established (in

306 terms of between gene regions), as the original ILD tests could not say which partitions were

307 incongruent, only that incongruence existed. An extra site which had consistently shown no

308 evidence of incongruence (LIW) was used as a control.

309

310 Following that, the datasets which continued to show incongruence had their ML trees input into

311 Dendroscope 3.0 (Huson and Scornavacca 2012), and pairwise tanglegrams were constructed to

312 identify the source of incongruence. In addition, tree hybridisation networks were created using

313 the Autumn algorithm (Huson and Linz 2016), implemented in Dendroscope 3.0. This algorithm

314 attempts to make a consensus tree from two input trees, and identifies the taxa that cannot be

315 reconciled. Finally, raw sequence alignments were inspected to verify incongruence in the

316 identified samples. All background sequences from populations related to putative hybrids were

317 also inspected in an effort to assess the likelihood of possible alternate explanations. 
319 Patterns of putative hybridisation (see Results) could potentially be verified by inspecting an

320 additional non-intragenomically variable nuclear marker. Therefore, the actin gene (symbiont

321 nuclear DNA) was sequenced for putative hybrid samples and closely related samples identified

322 in this study. Samples were PCR-amplified and directly sequenced in the forward direction by the

323 Macrogen Sequencing Service (Macrogen Inc., Seoul, South Korea) using the primer pair 324 actin_fl/actin_r1 (Pochon et al. 2012). An initial PCR run used a 7 min denaturation at $95^{\circ} \mathrm{C}$, 325 followed by 40 cycles of $94^{\circ} \mathrm{C}(40 \mathrm{~s}), 58^{\circ} \mathrm{C}(40 \mathrm{~s}), 72^{\circ} \mathrm{C}(90 \mathrm{~s})$ and a final denaturation of $10 \mathrm{~min}$ 326 at $72^{\circ} \mathrm{C}$. PCRs contained $1 \times$ MyTaq HS Red Mix (Bioline, Randolph, MA, USA), 20 ng sample 327 DNA, $10 \mu \mathrm{g}$ BSA, $0.25 \mu \mathrm{M}$ each primer, and $\mathrm{H}_{2} \mathrm{O}$ to a total volume of $20 \mu \mathrm{l}$. All samples had 328 multiple bands present (observed by running on a 1.5\% agarose gel), so the PCR product was run 329 on a $1 \%$ agarose gel for 1 h 30 min. Bands at the correct length ( 900 bp) were excised with a 330 pipette tip and reamplified using 20 cycles of the above conditions. Prior to sequencing, the 331 samples were purified with MagNA PCR clean-up solution (Rohland and Reich 2012). Sequences 332 were inspected visually, and no further steps were taken (see Discussion).

\section{Results}

335

336

Incongruence Length Difference tests

337

338 The $c o b, \mathrm{psbA}^{\mathrm{ncr}}$ and ITS2 gene partitions for Timor sites (HEW, LIE, LIW) were not incongruent, 339 a trend which was also seen in the overall Timor island analysis (ILD test, $\mathrm{p}=1$ for all). This $\mathrm{p}$ 340 value is not concerning; it simply indicates that among the replicates, the partitions were never 341 more parsimonious than random partitions. The Atauro dataset as a whole did not show statistically 
342 substantiated evidence of incongruence, though it approached significance $(\mathrm{p}=0.0874)$. In this

343 case, it is valid to use the term 'approaching significance', as the test statistic is directly correlated

344 to the number of replicates for which the original partitions were found to vary from random data

345 (Planet 2006). Looking at each Atauro site individually, BBR and BLS were not incongruent $(\mathrm{p}=$

346 0.99), while BHB displayed an equivocal result $(\mathrm{p}=0.129)$ and BSP was strongly incongruent

347 between partitions $(\mathrm{p}=0.001)$. However, these tests on three partitions could not identify where 348 potential incongruences were located.

Approximately Unbiased (AU) tests

In 24 of the 27 tests conducted, the best tree chosen was the one that was made from that gene region originally (i.e. for a test with the ITS2 region as its base, the ITS2 tree was chosen as the best tree). The exceptions were sites BBR, HEW and LIE, where either the $\mathrm{psbA}^{\mathrm{ncr}}$ or ITS2 trees were chosen as the best explanation of the $c o b$ dataset. The test always found incongruence when using the $\mathrm{psbA}^{\mathrm{ncr}}$ region as a base; this is likely due to an issue with the test (see Discussion), and therefore the results for the $c o b$ and ITS2 gene regions are the major focus of these results.

There was a very clear island-wide partitioning of results when it came to the AU test (Table 1). all three trees $(c o b$, ITS2, psbA ncr $)$ did an equally good job of explaining these two regions. While there was incongruence between $c o b$ and ITS2 trees using the ITS2 region as a base in the overall Timor analysis, this was not reciprocated (i.e. these two trees were not incongruent when considering the $c o b$ dataset). In contrast, the Atauro datasets showed high levels of reciprocal 
365 incongruence. Overall, the ITS2 tree (but not the $\mathrm{psbA}^{\text {ncr }}$ tree) made from all Atauro samples was

366 incongruent with the $c o b$ dataset, and both the $c o b$ and $\mathrm{psbA}^{\text {ncr }}$ trees were incongruent with the

367 ITS2 dataset. Looking at individual sites, the same complete reciprocal incongruence exists for the

368 BHB and BSP datasets. These three datasets (Atauro, BHB, BSP) correspond to the three lowest

369 p-values returned by the ILD tests. In general, the tests reveal incongruence between the organellar

$370\left(c o b\right.$ and $\left.\mathrm{psbA}^{\mathrm{ncr}}\right)$ and nuclear (ITS2) gene regions. In all cases, the AU test was unable to reject

371 congruence between the $c o b$ and $\mathrm{psbA}^{\mathrm{ncr}}$ regions. However, it did reject congruence between the

372 ITS2 and $\mathrm{psbA}^{\mathrm{ncr}}$ regions (using the ITS2 region as a base), and showed reciprocal incongruence

373 between the $c o b$ and ITS2 region (using both the ITS2 and $c o b$ regions as a base). In addition, the

374 ITS2 tree was incongruent with the $c o b$ dataset (but not the other way around) for site BLS. As

375 such, these four datasets (complete Atauro, BHB, BSP, BLS) were carried forward to post hoc 376 testing.

378 Post hoc analyses

Additional ILD tests were carried out using two partitions at a time. Site LIW was included as a control to ensure that the tests still successfully supported congruence where appropriate. These results strongly support the AU test (Table 2). There is clear incongruence between the nuclear ITS2 region and the other two organellar gene regions, which are not incongruent when considered together. Site LIW is clearly not incongruent at all regions. This shows that these two-way tests are functioning as expected. BLS is also not incongruent; while the AU test indicated potential incongruence, the other tests do not and so it was not carried forward as a candidate for hybridisation. Pairwise tanglegrams were made for BHB, BSP, and Atauro datasets, with 
388 potentially incongruent branches verified by attempting to hybridise the two trees to create a 389 consensus. Those branches and closely related sequences subsequently had their raw sequences 390 inspected in an attempt to confirm incongruence.

391

392 The tanglegrams and tree hybridisation analyses for site BHB (Fig. 2) support the results of the 393 statistical tests. Comparing the two organellar genes with the ITS2 region (Fig. 2a, 2b) reveals two 394 incongruent samples, BHB146 and BHB148, while BHB148 is also incongruent between the cob 395 and $\mathrm{psbA}^{\text {ncr }}$ regions (Fig. 2c). Inspection of raw sequence alignments reveals BHB146 is an 396 example of true incongruence (Fig. 3), whereas the incongruence in BHB148 is due to a highly divergent $\mathrm{psbA}^{\mathrm{ncr}}$ sequence, and does not show a reticulate pattern (Fig. S1). For the organellar gene regions, $\mathrm{BHB} 146$ belongs to the Cladocopium $\mathrm{C} 1$ radiation (symbiont types $\mathrm{C} 42 \mathrm{a}$ and $\mathrm{C} 1 \mathrm{v}$ respectively, see Brian et al. 2019). For the ITS2 region, it is identified as type C1\#, which groups more closely with the Cladocopium $\mathrm{C} 3$ radiation.

401

The BSP tanglegrams (Fig. 4) also support the statistical analyses, with six potentially incongruent 403 samples identified. After inspection of the raw sequence data, four of these were disregarded 404 (BSP211, BSP320, BSP372, BSP387), as they were more likely caused by parsimony405 uninformative mutations in a single sequence (Fig. S2). However, two samples were verified as 406 incongruent (BSP343 and BSP364, Figs. 5 and 6). BSP364 belongs to two different previously 407 defined subclades: a variant of Cladocopium type C40 for psbA ${ }^{\text {ncr }}$, and type C3z for ITS2. BSP343 408 also shows clear incongruence between the organellar and nuclear genes regions. The psbA $^{\text {ncr }}$ is a 409 variant of Cladocopium type C40, which groups it most closely with the psbA ${ }^{\text {ncr }}$ C3z clade (Fig. 
$4104 \mathrm{~b}$ ), while the ITS2 region features type C3u, which places it as distinct from both the C3z and 411 C40 groups.

412

413 Pairwise tanglegrams and hybridisation analyses were also executed for the whole Atauro Island 414 dataset (sites BBR, BHB, BLS, BSP). Despite the inclusion of two more sites, the analyses showed 415 that incongruence was caused by exactly the same samples as found by the individual site analyses, 416 affirming BHB and BSP as sites with incongruent samples. Further, no other sites contributed any 417 incongruent samples. The overall results are presented in Table 3, which demonstrates that ITS2 418 comparisons displayed the most incongruence, while any incongruences between $c o b$ and $\mathrm{psbA}^{\mathrm{ncr}}$ 419 regions were due to non-reticulate sequence variation. This is strongly supportive of the AU test 420 results as well as Table 2, which all indicate that incongruence occurs between the organellar and nuclear genomes of Cladocopium. Of the three clearly incongruent samples (BHB146, BSP343, BSP364) there was no general clear pattern in coral host (host genera: Pavona, Symphyllia and Acropora respectively). The sequencing of the actin gene was uninformative, with only occasional non-parsimonious variation observed (i.e. polymorphisms in a single sequence only). particularly fruitful for sample BSP364 (which has incongruent C3z and C40 genetic signals). At site BSP, there were eight additional samples with $\mathrm{C} 3 \mathrm{z}$ as the dominant ITS2 sequence (these were also $\mathrm{C} 3 \mathrm{z}$ for $\mathrm{psbA}^{\mathrm{ncr}}$ and cob regions), and thirteen with $\mathrm{C} 40$ as the dominant ITS2 sequence (these were also $\mathrm{C} 40$ for the $\mathrm{psbA}^{\mathrm{ncr}}$ and cob regions) at site BSP (Fig. 7). Of the eight C3z samples (Fig 7a), seven had no C40 sequences in their genomes, while one had C40 traces at a frequency of

$432 \quad 0.61 \%$ (Fig 7b). C40 samples had a low proportion of background sequences (Fig. 7c), and less 
433 than half of them possessed $\mathrm{C} 3 \mathrm{z}$ traces, which only appeared as the $3^{\text {rd }}$ most common background

434 sequence in terms of average abundance, and $5^{\text {th }}$ most common in terms of frequency (Fig. 7d).

435 The other two putative hybrid ITS2 types $(\mathrm{C} 3 \mathrm{u}, \mathrm{C} 1 \#)$ did not occur frequently enough to conduct

436 a similar analysis, but are mentioned in the Discussion.

437

438

439

440

441

442

443

444

445

446

447

448

449

450

451

452

453

454

455

\section{Methodological approach taken}

\section{Discussion}

There are many factors, such as character sampling and bias due to differential gene length, which can give false signals of incongruence (Som 2014). However, the approach taken in this study has been able to clearly display incongruence between organellar and nuclear regions in Cladocopium. In isolation, it is true that there are issues with the tests utilised. For example, the AU test presented an issue with most trees being incongruent for the $\mathrm{psbA}^{\mathrm{ncr}}$ region. The $\mathrm{psbA}^{\mathrm{ncr}}$ region is highly variable (LaJeunesse and Thornhill 2011; Thornhill et al. 2014), and hence a more complex tree is required to explain it. The $c o b$ and ITS2 trees with multiple polytomies could not do this as effectively, and hence a result of incongruence was returned. Therefore, the results from the $c o b$ and ITS2 datasets are likely more reliable, and were the focus of the Results. Further, the ILD test has been criticised for being overly sensitive, especially when comparing partitions of different resolutions (Barker and Lutzoni 2002). The refutation of this is simple: in all cases, it found congruence between the $\mathrm{psbA}^{\mathrm{ncr}}$ and $c o b$ regions, the two most different in terms of resolution (Table 2), so this is clearly not contributing to the positive results between the organellar and nuclear partitions observed here. Indeed, it failed to reject congruence between the $c o b$ and $\mathrm{psbA}^{\mathrm{ncr}}$ 
456 regions for sites $\mathrm{BSP}$ and $\mathrm{BHB}$ despite the tree hybridisation analyses finding potential

457 incongruence (Fig. 2c, 4c), and so appears to be reasonably conservative in this case. The results

458 of the AU and ILD tests are also compelling because they are differential: they show consistently

459 different patterns between datasets and are therefore likely responding to genuine phylogenetic

460 signals. This was confirmed by looking at the raw sequence data, and shows the efficacy of the

461 approach taken here. With such a wide range of samples, initially searching for incongruences in

462 sequence data would be functionally impossible, as it would require comparing all possible

463 combinations of sequences (in this study, this would require $1.17 \times 10^{278}$ comparisons). However,

464 the stepwise use of analyses allowed the initial identification of which sites may host incongruent

465 samples, and then visualisation on phylogenetic trees allowed simple alignments of appropriate

466 samples to be generated, where incongruence could clearly be refuted or confirmed. In addition,

467 given the issues with tests in isolation, the multiplicity of analyses used generates a far more

468 convincing picture of reticulate evolution.

469

470

Hybridisation in Cladocopium?

471

472 Incongruence was comprehensively established for the samples BHB146, BSP343 and BSP364.

473 However, this does not necessarily translate to hybridisation, as there are a range of analytical or

474 biological factors that can cause incongruence in phylogenetic data. For example, one

475 hypothesised to be quite common but insidious in its undetectable nature is heterotachy, shifts in

476 site-specific evolutionary rates through time (Som 2014). While there is no particular way to

477 identify heterotachy or exclude it as a cause, except with a very large number of sequences, 
478 maximum likelihood methods in particular have been shown to be robust to even intermediate

479 levels of heterotachy (Som 2014).

480

481 A more plausible explanation is incomplete lineage sorting (ILS), often considered the most 482 common cause of incongruence (Degnan and Rosenberg 2009). This is due to polymorphisms not segregating fully during speciation events, leading to phylogenetic signals in gene trees that conflict with the overall species tree. This has been shown to be quite common in the ITS2 region, thanks to its multiple-copy nature (Thornhill et al. 2007). Through this mechanism, ancestral polymorphisms may persist at low levels in the genome. Therefore, it is possible that the divergent sequences recovered actually represent a single symbiont population, which has multiple ancestral polymorphisms present via ILS (i.e. intragenomic variation). Through stochastic DNA processes such as unequal crossing over, slipped-strand mispairing and transposition, these intragenomic variants may be eliminated or promoted in the multiple-copy array (i.e. concerted evolution, see

Nei and Rooney 2005). Hence, in the samples from a single reproductively isolated population, one ancestral polymorphism may be dominant in the ITS2 region of some, while a different ancestral polymorphism may be dominant in others. This would cause the patterns observed in this study, with the ITS2 region being occasionally incongruent with the organellar regions.

Ideally, a statistical test would be carried out to differentiate between hybridisation and ILS, and such tests do exist. However, they require inputs of information which are not currently available for Cladocopium, such as: (a) An understanding of the effective population size $N_{e}$ (Pelser et al. 2010); (b) a large number of genes, at least some of which must be adjacent (Pollard et al. 2006; 
501 Zhong 2000; Joly et al. 2009). Therefore, ILS as a cause of the observed incongruence cannot be

502 statistically refuted. However, there is good evidence that the patterns observed here are more

503 likely to be caused by symbiont hybridisation.

504

505 First, the pattern of incongruence observed, with organellar cytoplasmic genes being different to 506 nuclear genes, accords with a large body of prior theory on hybridisation. Nuclear genes are largely 507 inherited biparentally, and the ITS2 region is no exception (Baldwin et al. 1995; Rybalka et al. 508 2013). However, the cytoplasm tends to be inherited maternally (Rieseberg et al. 1996). This 509 difference is largely due to gametogenesis and fertilisation, where the male gamete typically only contains nuclear information, while the female gamete (egg) contains the cytoplasm that will be

511 passed on to the zygote. Therefore, if an organism encounters a population of another species and 512 produces viable hybrids, theory predicts that over time, repeated backcrossing with the more 513 common species (introgression) will produce hybrids with divergent organellar and nuclear 514 signals. While the nature of the sexual life cycle has yet to be fully elucidated in the 515 Symbiodiniaceae, previous evidence has shown that other unicellular dinoflagellates produce 516 gametes (Brawley and Johnson 1992). In addition, the presence of 'plus' and 'minus' mating types,

517 analogous to gender, has been shown in the dinoflagellate Alexandrium tamarense (Brosnahan 518 2011). Therefore, it is reasonable to assume that Symbiodiniaceae also produce distinct gametes 519 (as opposed to conducting sex via fusion, for example), making this mechanism eminently 520 plausible. The documentation of functional meiotic genes in Symbiodiniaceae (Chi et al. 2014, 521 Levin et al. 2016) supports this assertion. Such a pattern of discordance between cytoplasmic and 522 nuclear genes caused by hybridisation has been recorded for taxa as diverse as plants (Rieseberg 523 et al. 1996; Pelser et al. 2010; Sun et al. 2015), beetles (Sota and Vogler 2001) and indeed corals 
524 (van Oppen et al. 2001). In general, hybridisation is predicted to cause incongruence between

525 nuclear and cytoplasmic markers in both multicellular and unicellular taxa (Bull et al. 1993). Other

526 factors due to hybridisation, such as semigamy or differential fitness of nuclear-cytoplasmic

527 combinations, can also cause incongruence between nuclear and cytoplasmic gene trees (Rieseberg

528 et al. 1996). Therefore, the fact that this was the pattern observed in this study is strong

529 circumstantial evidence that hybridisation is the explanation.

530

531 In addition, hybridisation is made more likely in comparison to ILS by the fact that all of the

532 incongruent ITS2 sequences were previously defined types (i.e. not unique sequences), that were

533 also present in non-incongruent relationships in the analyses. For example, BSP364 had a generic

534 Cladocopium type $\mathrm{C} 3$ sequence for the $c o b$ gene, was a $\mathrm{C} 40$ type for the $\mathrm{psbA}^{\mathrm{ncr}}$ region, and $\mathrm{C} 3 \mathrm{z}$

535 for the ITS2 region. Significantly, there were also samples recovered which were type C40 for

536 both the $\mathrm{psbA}^{\mathrm{ncr}}$ and ITS2 regions (samples BSP319-BSP375, Fig. 4b), and samples which were

537 type $\mathrm{C} 3 \mathrm{z}$ for both regions (samples BSP373-BSP386, Fig. 4b). This confirms that they are clearly

538 separate types, supported by the fact that they differ by four base pairs in the ITS 2 sequence and

53964 base pairs in the psbA ${ }^{\text {ncr }}$ region (including a 49 base pair deletion in the C40 sequences),

540 indicating that this is not just a non-diagnostic polymorphism (Wilkinson et al. 2015). The

541 implications for this being caused by ILS are given in Fig. 8. Only the psbA ${ }^{\text {ncr }}$ and ITS2 genes are

542 presented, as the cob gene was invariant in this case.

543

544 Fig. 8b graphically represents the process that would be required for the observed patterns to be

545 due to ILS. Given that symbiont sex is now strongly supported (though in low frequency; Thornhill

546 et al. 2017), it seems unlikely that a divergent ancestral polymorphism could be maintained as the 
547 dominant sequence in some samples within type $\mathrm{C} 40$, as it would be expected that repeated

548 recombination would eventually remove $\mathrm{C} 3 \mathrm{z}$ traces from the $\mathrm{C} 40$ genome, or vice versa (Fig. 8a).

549 It is more parsimonious that a hybridisation event has occurred between symbiont types C40 and

$550 \mathrm{C} 3 \mathrm{z}$, with backcrossing leading to incongruence between organellar and nuclear genes. This is

551 strongly supported by the analysis of the background symbiont populations (Fig. 7). The results

552 show that there is little evidence of $\mathrm{C} 40$ and $\mathrm{C} 3 \mathrm{z}$ sequences being shared within samples. The $\mathrm{C} 3 \mathrm{z}$

553 population had almost no $\mathrm{C} 40$ sequences present at all, with just one sample having an extremely

554 low background abundance of C40 (Fig. 7b). C3z sequences were slightly more common in C40

555 samples (Fig. 7d). However, the low proportion of background sequences in this population (Fig.

556 7c) meant that overall the presence of $\mathrm{C} 3 \mathrm{z}$ in the $\mathrm{C} 40$ population was negligible (mean $=1.61 \%$,

557 median $=0$ ). This reveals essentially pure populations of $\mathrm{C} 40$ and $\mathrm{C} 3 \mathrm{z}$ at site $\mathrm{BSP}$, something

558 which strongly favours hybridisation versus ILS as causing the mixed pattern in BSP364

559 (Wilkinson et al. 2015). While the other two putative hybrid ITS2 types (C3u, C1\#) do not have

560 large populations to compare, the same basic pattern was also observed for BSP343, which was

561 identified as Cladocopium type C40 for the organelle regions, and type C3u for ITS2. If this was

562 to be caused by ILS, then both variants would be expected to occur in the ITS2 region, (with one

563 at low frequency), but the NGS data revealed no trace of ITS2 type C40 in that sample. Further,

564 the divergences observed (i.e. $\mathrm{C} 40 / \mathrm{C} 3 \mathrm{u}, \mathrm{C} 40 / \mathrm{C} 3 \mathrm{z}, \mathrm{C} 1 / \mathrm{C} 1 \#$ ) all coalesce at the 'ancestral' types $\mathrm{C} 1$

565 or C3, rather than one representing an intermediate evolutionary step to the other. Therefore, ILS

566 would also predict these ancestral sequences to be in the ITS2 genome in low frequencies.

567 However, this was only observed in BSP343 (as the fourth most common sequence); neither

568 BHB146 nor BSP364 showed any evidence of these ancestral sequences. While it is acknowledged

569 that hybridisation and ILS are not mutually exclusive and the incongruences observed could be 
570

571

572

573 Potentially, the two competing hypotheses could be distinguished by sequencing another nuclear 574

575

576

577

578

579

580

581

582

583

584

585

586

587

588

589

590

591

592

caused by a combination of both, the weight of evidence suggests that these results are more likely a result of interspecific hybridisation between distinct symbiont types.

gene, less susceptible to intragenomic variation, for both putative hybrid samples and closely related sequences. If the patterns were due to hybridisation, it would be expected that the additional nuclear gene would support the ITS2 identity, and cluster the sample with the same group as presented in the ITS2 trees (Figs. 2, 4). In contrast, if the incongruence was caused by ILS, the additional marker would cluster the putative hybrid with the same samples as the organellar gene regions. This was attempted using the actin gene. Unfortunately, low resolution (and difficulties in amplification leading to short usable sequences) meant that neither scenario was supported, as the sequences were not variable enough to recover the groups observed in Figures 2 and 4 . The other currently-available Symbiodiniaceae nuclear gene markers either suffer from the same issue of significant intragenomic variation (ITS1), or are lower-resolution than actin (SSU, LSU, 5.8S, elf2), and therefore the patterns observed cannot currently be independently verified. The further development of highly-variable, reliably amplifiable nuclear gene markers should be a priority for Symbiodiniaceae systematics. However, ILS (and indeed all analytical factors), are random or would be expected to affect all sites. The results obtained, however, are anything but random, with two sites consistently being recovered as incongruent in contrast to all others, despite those incongruences coming from a range of host species that were present at all sites. In addition, both these sites have been shown to be rich in Symbiodiniaceae diversity, when compared with the Timor sites (Brian et al. 2019). This suggests that putative hybridisation may be limited to highquality sites that maintain high levels of symbiont diversity. 
594 Intragenomic variation within the ITS2 region could lead to the incongruences observed via ILS, 595 though the discussion above suggests that hybridisation should be favoured as an explanation. 596 However, the psbA $^{\text {ncr }}$ region can also be intragenomically variable (LaJeunesse and Thornhill 597 2011), with intragenomic sequence ratios that may fluctuate within a single species. Combined 598 with the intragenomic variation of the ITS2 region, this generates the potential for a wide range of 599 ITS2-psbA ${ }^{\text {ncr }}$ combinations within a single genome. For example, one member of a population 600 may have a 9:1 ratio of variant A:variant B within its multiple-copy ITS2 sequences, and a 9:1 601 ratio of variant $\mathrm{A}$ :variant $\mathrm{B}$ in its multiple-copy $\mathrm{psbA}^{\mathrm{ncr}}$ sequences. A second member of the same 602 population could plausibly have an 8:2 ratio of variant A:variant B within its ITS2 sequences, and 603 a 4:6 ratio of variant A:variant $B$ in its $\operatorname{psbA}^{\text {ncr }}$ sequences. Therefore, there is a possible difference 604 between the most common sequences in total, and the most common associations between ITS2 605 and $\mathrm{psbA}^{\mathrm{ncr}}$ ratio types. If only the most common sequences are studied, there is the potential for 606 some natural associations (i.e. not caused by hybridisation) to appear as incongruences. The 607 present study attempts to draw conclusions based on common associations between nuclear and 608 organellar genes, but is only able to utilise common sequences. This is explicit for the $\mathrm{psbA}^{\mathrm{ncr}}$ 609 region (as Sanger sequencing only amplifies the most common overall sequence), and implicit for 610 the ITS2 region (as the nature of the tests necessitated the selection of the most common overall 611 sequence from NGS data). Within a single genome, a solution would be to sequence multiple 612 markers from the same DNA strand through long-read sequencing, which would preserve the ratio 613 of intragenomic variants. However, this does not work for markers across multiple organellar and 614 nuclear genomes, and currently there is no other acceptable solution to this problem for 
615 Symbiodiniaceae. While perhaps unlikely, this issue could potentially explain the patterns seen,

616 and should be acknowledged.

617 Previous tests of incongruence

618

619 No previous study on Symbiodiniaceae seriously considers symbiont hybridisation, except that of 620 Wilkinson et al. (2015), which also finds evidence for its existence. However, aside from the 621 potential examples of hybridisation mentioned in the Introduction of this study (LaJeunesse et al. 622 2003, 2004; LaJeunesse 2005), three other studies bear mention. Sampayo et al. (2009) also 623 focused on the basis that hybridisation can cause incongruence between genes from different 624 organelles, and built trees from mitochondrial, chloroplast and rDNA nuclear gene regions to test 625 this. Based on visual inspection of these trees, they concluded that different symbiont lineages 626 (types) within Cladocopium are reproductively isolated. Interestingly, they did also use the ILD 627 test to formally test incongruence, which returned a p-value of 0.01 , though this result was not 628 explored further. Pochon et al. (2014) assessed six genes from three different organelles 629 (mitochondrion, nucleus and chloroplast). In all cases, they found evidence of incongruence 630 between pairwise comparisons of genes, using the AU test. While they go on to discuss the 631 implications for concatenation in some detail, the cause of these incongruences was likewise not 632 explored further. Another study from Pochon et al. (2006) found the surprising result of 633 incongruence between whole genera rendered from nr28S and cp23S data, using the Shimodaira634 Hasegawa test. However, when they removed all but two members of each clade, the test then 635 showed congruence between datasets. This indicated incongruence was being caused by the 636 accumulation of occasional within-clade mismatches between the nucleus and chloroplasts, 637 something which is also broadly agreeable with a hypothesis of hybridisation in low frequency. 
638 These studies certainly do not provide conclusive evidence of hybridisation. However, it is 639 reasonably striking that four studies conduct an explicit statistical test of incongruence within 640 Symbiodiniaceae (Pochon et al. 2006, 2014; Sampayo et al. 2009; this study), and all four find 641 evidence for its existence. At the very least, these add to the body of evidence that the family 642 Symbiodiniaceae has not evolved in a simple linear fashion, and justifies a more careful 643 consideration of patterns of incongruence within this family.

644

645 Conclusions

646

647 This study cannot be considered unequivocal proof of Cladocopium hybridisation. However, the 648 unambiguous evidence for incongruence between nuclear and organellar gene regions shows the 649 value of the stepwise approach taken here, and conforms to the hypothesis of hybridisation 650 between divergent taxa. While incomplete lineage sorting remains a possibility, it is a less intuitive 651 explanation, especially in the light of incongruent samples having clearly distinct, predefined types 652 which were recovered in non-incongruent samples, and the failures of background populations to 653 consistently align to its predictions. Therefore, hybridisation appears to be a credible, if infrequent, 654 mechanism for adaptive change in Cladocopium, and potentially for Symbiodiniaceae in general, 655 though multiple sources of intragenomic variation remain analytically problematic. Ascertaining 656 the frequency and extent of this may be vital to predicting the fate of coral reefs in an 657 environmentally unpredictable future.

658

\section{Acknowledgements}


661 Evan Raymond assisted with the optimisation of actin gene sequencing. We are grateful to two

662 anonymous reviewers, whose comments improved the quality of this manuscript.

663

664

\section{References}

665

666

667

668

669

670

671

672

673

674

675

676

677

678

679

680

681

682

683

684

685

686

687

688

689

690

691

692

693

694

Baillie BK, Belda-Baillie CA, Silvestre V, Sison M, Gomez AV, Gomez ED, Monje V (2000) Genetic variation in Symbiodinium isolates from giant clams based on random-amplifiedpolymorphic DNA (RAPD) patterns. Marine Biology, 136, 829-836.

Baldwin BG, Sanderson MJ, Porter JM, Wojciechowski MF, Campbell CS, Donoghue MJ (1995) The ITS region of nuclear ribosomal DNA: a valuable source of evidence on angiosperm phylogeny. Annals of the Missouri Botanical Garden, 247-277.

Barker FK, Lutzoni FM (2002) The utility of the incongruence length difference test. Systematic Biology, 51, 625-637.

Baskett ML, Gaines SD, Nisbet RM (2009) Symbiont diversity may help coral reefs survive moderate climate change. Ecological Applications, 19, 3-17.

Baums IB, Devlin-Durante MK, LaJeunesse TC (2014) New insights into the dynamics between reef corals and their associated dinoflagellate endosymbionts from population genetic studies. Molecular Ecology, 23, 4203-4215.

Brawley SH, Johnson LE (1992) Gametogenesis, gametes and zygotes: an ecological perspective on sexual reproduction in the algae. British Phycological Journal, 27, 233-252.

Brian JI, Davy SK, Wilkinson SP (2019) Elevated Symbiodiniaceae richness at Atauro Island (Timor-Leste): a highly biodiverse reef system. Coral Reefs, 38, 123-136

Brosnahan, ML (2011) Life cycle studies of the red tide dinoflagellate species complex Alexandrium tamarense. Doctoral dissertation, Massachusetts Institute of Technology.

Bull JJ, Huelsenbeck JP, Cunningham CW, Swofford DL, Waddell PJ (1993) Partitioning and combining data in phylogenetic analysis. Systematic Biology, 42, 384-397.

695 
696 Charlton ND, Craven KD, Afkhami ME, Hall BA, Ghimire SR, Young CA (2014) Interspecific

697

698

699

700

701

702

703

704

705

706

707

708

709

710

711

712

713

714

715

716

717

718

719

720

721

722

723

724

725

726

727

728

729

730

731

732

733

734 hybridization and bioactive alkaloid variation increases diversity in endophytic Epichloë species of Bromus laevipes. FEMS Microbiology Ecology, 90, 276-289.

Chesnick JM, Cox ER (1987) Synchronized sexuality of an algal symbiont and its dinoflagellate host, Peridinium balticum (Levander) Lemmermann. Biosystems, 21, 69-78.

Chi J, Parrow MW, Dunthorn M (2014) Cryptic sex in Symbiodinium (Alveolata, Dinoflagellata) is supported by an inventory of meiotic genes. Journal of Eukaryotic Microbiology, 61, 322-327.

Coffroth MA, Lewis CF, Santos SR, Weaver JL (2006) Environmental populations of symbiotic dinoflagellates in the genus Symbiodinium can initiate symbioses with reef cnidarians. Current Biology, 16, R985-R987.

Combosch DJ, Vollmer SV (2015) Trans-Pacific RAD-Seq population genomics confirms introgressive hybridization in Eastern Pacific Pocillopora corals. Molecular Phylogenetics and Evolution, 88, 154-162.

Davy SK, Allemand D, Weis VM (2012) Cell biology of cnidarian-dinoflagellate symbiosis. Microbiology and Molecular Biology Reviews, 76, 229-261.

Degnan JH, Rosenberg NA (2009) Gene tree discordance, phylogenetic inference, and the multispecies coalescent. Trends in Ecology and Evolution, 24, 332-340.

Dittrich-Reed DR, Fitzpatrick BM (2013) Transgressive hybrids as hopeful monsters. Evolutionary Biology, 40, 310-315.

Edvardsen B, Shalchian-Tabrizi K, Jakobsen KS, Medlin LK, Dahl E, Brubak S, Paasche E (2003) Genetic variability and molecular phylogeny of Dinophysis species (Dinophyceae) from Norwegian waters inferred from single cell analyses of rDNA. Journal of Phycology, 39, 395-408.

Ellstrand NC, Hoffman CA (1990) Hybridization as an avenue of escape for engineered genes. Bioscience, 40, 438-442.

Farris JS, Källersjö M, Kluge AG, Bult C (1994) Testing significance of incongruence. Cladistics, 10, 315-319. 
735

736

737

738

739

740

741

742

743

744

745

746

747

748

749

750

751

752

753

754

755

756

757

758

759

760

761

762

763

764

765

766

767

768

769

770

771

772

773

774
Franklin EC, Stat M, Pochon X, Putnam HM, Gates RD (2012) GeoSymbio: a hybrid, cloudbased web application of global geospatial bioinformatics and ecoinformatics for Symbiodinium-host symbioses. Molecular Ecology Resources, 12, 369-373.

Folk RA, Mandel JR, Freudenstein JV (2017) Ancestral gene flow and parallel organellar genome capture result in extreme phylogenomic discord in a lineage of angiosperms. Systematic Biology, 66, 320-337.

Geneious version 8.0.5 created by Biomatters. Available from http://www.geneious.com

Goldman N, Anderson JP, Rodrigo AG (2000) Likelihood-based tests of topologies in phylogenetics. Systematic Biology, 49, 652-670.

Govindarajulu R, Parks M, Tennessen JA, Liston A, Ashman TL (2015) Comparison of nuclear, plastid, and mitochondrial phylogenies and the origin of wild octoploid strawberry species. American Journal of Botany, 102, 544-554.

Gribble KE, Anderson DM (2007) High intraindividual, intraspecific, and interspecific variability in large-subunit ribosomal DNA in the heterotrophic dinoflagellates Protoperidinium, Diplopsalis, and Preperidinium (Dinophyceae). Phycologia, 46, 315 324.

Hart MC, Green DH, Bresnan E, Bolch CJ (2007) Large subunit ribosomal RNA gene variation and sequence heterogeneity of Dinophysis (Dinophyceae) species from Scottish coastal waters. Harmful Algae, 6, 271-287.

Heitman J (2010) Evolution of eukaryotic microbial pathogens via covert sexual reproduction. Cell Host \& Microbe, 8, 86-99.

Hughes TP, Kerry JT, Álvarez-Noriega M, Álvarez-Romero JG, Anderson KD, Baird AH, ..., Bridge TC (2017) Global warming and recurrent mass bleaching of corals. Nature, 543, 373.

Huson DH, Scornavacca C (2012). Dendroscope 3: an interactive tool for rooted phylogenetic trees and networks. Systematic biology, 61, 1061-1067.

Huson DH, Linz S (2016) Autumn Algorithm-Computation of Hybridization Networks for Realistic Phylogenetic Trees. IEEE/ACM transactions on computational biology and bioinformatics. 
775

776

777

778

779

780

781

782

783

784

785

786

787

788

789

790

791

792

793

794

795

796

797

798

799

800

801

802

803

804

805

806

807

808

809

810

811

812

813

814

Joly S, McLenachan PA, Lockhart PJ (2009) A statistical approach for distinguishing hybridization and incomplete lineage sorting. The American Naturalist, 174, E54-E70.

Kemp DW, Thornhill DJ, Rotjan RD, Iglesias-Prieto R, Fitt WK, Schmidt GW (2015) Spatially distinct and regionally endemic Symbiodinium assemblages in the threatened Caribbean reef-building coral Orbicella faveolata. Coral Reefs, 34, 535-547.

Kirtman B, Power SB, Adedoyin AJ, Boer GJ, Bojariu R, Camilloni I, ..., Prather M (2013) Near-term climate change: projections and predictability. In: Climate Change 2013: The Physical Science Basis. Contribution of Working Group I to the Fifth Assessment Report of the Intergovernmental Panel on Climate Change (eds. Stocker TF, Qin D, ..., Plattner GK). Cambridge University Press, Cambridge.

Kishino H, Miyata T, Hasegawa M (1990) Maximum likelihood inference of protein phylogeny and the origin of chloroplasts. Journal of Molecular Evolution, 31, 151-160.

LaJeunesse TC (2001) Investigating the biodiversity, ecology, and phylogeny of endosymbiotic dinoflagellates in the genus Symbiodinium using the internal transcribed spacer region: in search of a "species" level marker. Journal of Phycology, 37, 866-880.

LaJeunesse TC (2005) "Species" radiations of symbiotic dinoflagellates in the Atlantic and IndoPacific since the Miocene-Pliocene transition. Molecular Biology and Evolution, 22, 570581.

LaJeunesse TC, Thornhill DJ (2011) Improved resolution of reef-coral endosymbiont (Symbiodinium) species diversity, ecology, and evolution through psbA non-coding region genotyping. PLoS One, 6, e29013.

LaJeunesse TC, Loh WK, van Woesik R, Hoegh-Guldberg O, Schmidt GW, Fitt WK (2003) Low symbiont diversity in southern Great Barrier Reef corals, relative to those of the Caribbean. Limnology and Oceanography, 48, 2046-2054.

LaJeunesse TC, Wham DC, Pettay DT, Parkinson JE, Keshavmurthy S, Chen CA (2014) Ecologically differentiated stress-tolerant endosymbionts in the dinoflagellate genus Symbiodinium (Dinophyceae) Clade D are different species. Phycologia, 53, 305-319.

LaJeunesse TC, Parkinson JE, Gabrielson PW, Jeong HJ, Reimer JD, Voolstra CR, Santos SR (2018) Systematic revision of Symbiodiniaceae highlights the antiquity and diversity of coral endosymbionts. Current Biology, 28, 2570-2580.

Peer] reviewing PDF | (2019:03:36008:1:1:CHECK 17 May 2019) 
815 LaJeunesse TC, Bhagooli R, Hidaka M, DeVantier L, Done T, Schmidt GW, ..., Hoegh816 Guldberg O (2004) Closely related Symbiodinium spp. differ in relative dominance in

817

818

819

820

821

822

823

824

825

826

827

828

829

830

831

832

833

834

835

836

837

838

839

840

841

842

843

844

845

846

847

848

849

850

851

852

853

854 coral reef host communities across environmental, latitudinal and biogeographic gradients. Marine Ecology Progress Series, 284, 147-161.

Law R, Lewis DH (1983) Biotic environments and the maintenance of sex-some evidence from mutualistic symbioses. Biological Journal of the Linnean Society, 20, 249-276.

Levin RA, Beltran VH, Hill R, Kjelleberg S, McDougald D, Steinberg PD, van Oppen MJ (2016) Sex, scavengers, and chaperones: transcriptome secrets of divergent Symbiodinium thermal tolerances. Molecular Biology and Evolution, 33, 2201-2215.

Meng C, Kubatko LS (2009) Detecting hybrid speciation in the presence of incomplete lineage sorting using gene tree incongruence: a model. Theoretical Population Biology, 75, 3545 .

Moon CD, Craven KD, Leuchtmann A, Clement SL, Schardl CL (2004) Prevalence of interspecific hybrids amongst asexual fungal endophytes of grasses. Molecular Ecology, 13, $1455-1467$.

Moore RB, Ferguson KM, Loh WK, Hoegh-Guldberg O, Carter DA (2003) Highly organized structure in the non-coding region of the psbA minicircle from clade C Symbiodinium. International Journal of Systematics and Evolutionary Microbiology, 53, 1725-1734.

Moran EV, Alexander JM (2014) Evolutionary responses to global change: lessons from invasive species. Ecology Letters, 17, 637-649.

Nei M, Rooney AP (2005) Concerted and birth-and-death evolution of multigene families. Annual Review of Genetics, 39, 121-152.

Nitschke, M. R., Davy, S. K., \& Ward, S. (2016). Horizontal transmission of Symbiodinium cells between adult and juvenile corals is aided by benthic sediment. Coral Reefs, 35, 335-344.

Pelser PB, Kennedy AH, Tepe EJ, Shidler JB, Nordenstam B, Kadereit JW, Watson LE (2010) Patterns and causes of incongruence between plastid and nuclear Senecioneae (Asteraceae) phylogenies. American Journal of Botany, 97, 856-873.

Pettay DT, Wham DC, Pinzon JH, LaJeunesse TC (2011) Genotypic diversity and spatialtemporal distribution of Symbiodinium clones in an abundant reef coral. Molecular Ecology, 20, 5197-5212.

Peer] reviewing PDF | (2019:03:36008:1:1:CHECK 17 May 2019) 
855

856

857

858

859

860

861

862

863

864

865

866

867

868

869

870

871

872

873

874

875

876

877

878

879

880

881

882

883

884

885

886

887

888

889

890

891

892

893

Planet PJ (2006) Tree disagreement: measuring and testing incongruence in phylogenies. Journal of Biomedical Informatics, 39, 86-102.

Pochon X, Putnam HM, Gates RD (2014) Multi-gene analysis of Symbiodinium dinoflagellates: a perspective on rarity, symbiosis, and evolution. PeerJ, 2, e394.

Pochon X, Pawlowski J, Zaninetti L, Rowan R (2001) High genetic diversity and relative specificity among Symbiodinium-like endosymbiotic dinoflagellates in soritid foraminiferans. Marine Biology, 139, 1069-1078.

Pochon X, Montoya-Burgos JI, Stadelmann B, Pawlowski J (2006) Molecular phylogeny, evolutionary rates, and divergence timing of the symbiotic dinoflagellate genus Symbiodinium. Molecular Phylogenetics and Evolution, 38, 20-30.

Pochon X, Putnam HM, Burki F, Gates RD (2012) Identifying and characterizing alternative molecular markers for the symbiotic and free-living dinoflagellate genus Symbiodinium. PLoS One, 7, e29816.

Pollard DA, Iyer VN, Moses AM, Eisen MB (2006) Widespread discordance of gene trees with species tree in Drosophila: evidence for incomplete lineage sorting. PLoS Genetics, 2 , e173.

Rhymer JM, Simberloff D (1996) Extinction by hybridization and introgression. Annual Review of Ecology and Systematics, 27, 83-109.

Rieseberg LH, Whitton J, Linder CR (1996) Molecular marker incongruence in plant hybrid zones and phylogenetic trees. Acta Botanica Neerlandica, 45, 243-262.

Robinson DA, Monk AB, Cooper JE, Feil EJ, Enright MC (2005) Evolutionary genetics of the accessory gene regulator (agr) locus in Staphylococcus aureus. Journal of Bacteriology, 187, 8312-8321.

Rodriguez RJ, White JF, Arnold AE, Redman RS (2009) Fungal endophytes: diversity and functional roles. New Phytologist, 182, 314-330.

Rohland N, Reich D (2012) Cost-effective, high-throughput DNA sequencing libraries for multiplexed target capture. Genome Res, 22, 939-946. 
894

895

896

897

898

899

900

901

902

903

904

905

906

907

908

909

910

911

912

913

914

915

916

917

918

919

920

921

922

923

924

925

926

927

928

929

930

931

932

933

Rybalka N, Wolf M, Andersen RA, Friedl T (2013) Congruence of chloroplast-and nuclearencoded DNA sequence variations used to assess species boundaries in the soil microalga Heterococcus (Stramenopiles, Xanthophyceae). BMC Evolutionary Biology, 13, 39.

Sampayo EM, Dove S, LaJeunesse TC (2009) Cohesive molecular genetic data delineate species diversity in the dinoflagellate genus Symbiodinium. Molecular Ecology, 18, 500-519.

Sang T, Zhong Y (2000) Testing hybridization hypotheses based on incongruent gene trees. Systematic Biology, 49, 422-434.

Santos SR, Coffroth MA (2003) Molecular genetic evidence that dinoflagellates belonging to the genus Symbiodinium Freudenthal are haploid. The Biological Bulletin, 204, 10-20.

Santos SR, Taylor DJ, Coffroth MA (2001) Genetic comparisons of freshly isolated versus cultured symbiotic dinoflagellates: implications for extrapolating to the intact symbiosis. Journal of Phycology, 37, 900-912.

Santos SR, Shearer TL, Hannes AR, Coffroth MA (2004) Fine-scale diversity and specificity in the most prevalent lineage of symbiotic dinoflagellates (Symbiodinium, Dinophyceae) of the Caribbean. Molecular Ecology, 13, 459-469.

Schardl CL, Leuchtmann A, Tsai HF, Collett MA, Watt DM, Scott DB (1994) Origin of a fungal symbiont of perennial ryegrass by interspecific hybridization of a mutualist with the ryegrass choke pathogen, Epichloe typhina. Genetics, 136, 1307-1317.

Shimodaira H (2002) An approximately unbiased test of phylogenetic tree selection. Systems Biology, 51, 492-508.

Shimodaira H, Hasegawa M (1999) Multiple comparisons of log-likelihoods with applications to phylogenetic inference. Molecular Biology and Evolution, 16, 1114-1116.

Shymanovich T, Charlton ND, Musso AM, Scheerer J, Cech NB, Faeth SH, Young CA (2017) Interspecific and intraspecific hybrid Epichloë species symbiotic with the North American native grass Poa alsodes. Mycologia, 109, 459-474.

Som A (2014) Causes, consequences and solutions of phylogenetic incongruence. Briefings in Bioinformatics, 16, 536-548.

Sota T, Vogler AP (2001) Incongruence of mitochondrial and nuclear gene trees in the carabid beetles Ohomopterus. Systematic Biology, 50, 39-59. 
934

935

936

937

938

939

940

941

942

943

944

945

946

947

948

949

950

951

952

953

954

955

956

957

958

959

960

961

962

963

964

965

966

967

968

969

970

971

972

973
Stat M, Pochon X, Cowie RO, Gates RD (2009) Specificity in communities of Symbiodinium in corals from Johnston Atoll. Marine Ecology Progress Series, 386, 83-96.

Strimmer K, Rambaut A (2002) Inferring confidence sets of possibly misspecified gene trees. Proceedings of the Royal Society of London B: Biological Sciences, 269, 137-142.

Sun M, Soltis DE, Soltis PS, Zhu X, Burleigh JG, Chen Z (2015) Deep phylogenetic incongruence in the angiosperm clade Rosidae. Molecular Phylogenetics and Evolution, 83, 156-166.

Swofford DL (2002) PAUP*. Phylogenetic Analysis Using Parsimony (*and Other Methods). Version 4.0a161. Sinauer Associates, Sunderland, Massachusetts

Thornhill DJ, LaJeunesse TC, Santos SR (2007) Measuring rDNA diversity in eukaryotic microbial systems: how intragenomic variation, pseudogenes, and PCR artifacts confound biodiversity estimates. Molecular Ecology, 16, 5326-5340.

Thornhill DJ, Lewis AM, Wham DC, LaJeunesse TC (2014) Host-specialist lineages dominate the adaptive radiation of reef coral endosymbionts. Evolution, 68, 352-367.

Thornhill DJ, Howells EJ, Wham DC, Steury TD, Santos SR (2017) Population genetics of reef coral endosymbionts (Symbiodinium, Dinophyceae). Molecular Ecology, 26, 2640-2659.

Trench RK (1997) Diversity of symbiotic dinoflagellates and the evolution of microalgalinvertebrate symbioses. In Proceedings of the 8th International Coral Reef Symposium, 2 , 1275-1286.

Tsai HF, Liu JS, Staben C, Christensen MJ, Latch GC, Siegel MR, Schardl CL (1994) Evolutionary diversification of fungal endophytes of tall fescue grass by hybridization with Epichloë species. Proceedings of the National Academy of Sciences, 91, 2542-2546.

van Oppen MJH, McDonald BJ, Willis B, Miller DJ (2001) The evolutionary history of the coral genus Acropora (Scleractinia, Cnidaria) based on a mitochondrial and a nuclear marker: reticulation, incomplete lineage sorting, or morphological convergence?. Molecular Biology and Evolution, 18, 1315-1329.

van Oppen MJH, Oliver JK, Putnam HM, Gates RD (2015) Building coral reef resilience through assisted evolution. Proceedings of the National Academy of Sciences, 112, 23072313. 
974

975 Wilkinson SP, Fisher PL, van Oppen MJH, Davy SK (2015) Intra-genomic variation in

976

977

978

979

980

981

982

983

984

985

986

987 symbiotic dinoflagellates: recent divergence or recombination between lineages?, $B M C$ Evolutionary Biology, 15, 46.

Willis BL, van Oppen MJH, Miller DJ, Vollmer SV, Ayre DJ (2006) The role of hybridization in the evolution of reef corals. Annual Review of Ecology, Evolution, and Systematics, 37, 489-517.

Zhang H, Bhattacharya D, Lin S (2005) Phylogeny of dinoflagellates based on mitochondrial cytochrome B and nuclear small subunit rDNA sequence comparisons. Journal of Phycology, 41, 411-420. 
Figure 1 (on next page)

Stepwise analyses performed per site to identify incongruences in Cladocopium. 
Overall Incongruence Length

\section{Difference test}

\section{PeerJ}

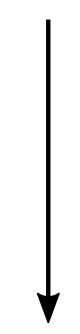

Approximately Unbiased test

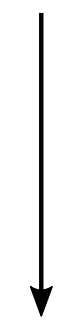

Pairwise Incongruence Length

Difference tests

Pairwise tanglegram construction

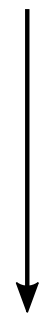

Tree hybridisation analysis 
Figure 2 (on next page)

Pairwise tanglegrams for site BHB.

Red branches with bolded taxa labels indicate incongruent samples, as identified by the tree hybridisation analysis (executed in Dendroscope 3.0 [Huson and Linz 2016]). Branch labels are ML bootstrap values (1000 replicates for cob, 100 for ITS2 and psbAncr). (a) cob vs. ITS2: found incongruent by ILD and AU tests. (b) psbAncr vs. ITS2: found incongruent by ILD and AU tests. (c) cob vs. psbAncr: found congruent by ILD and AU tests. 

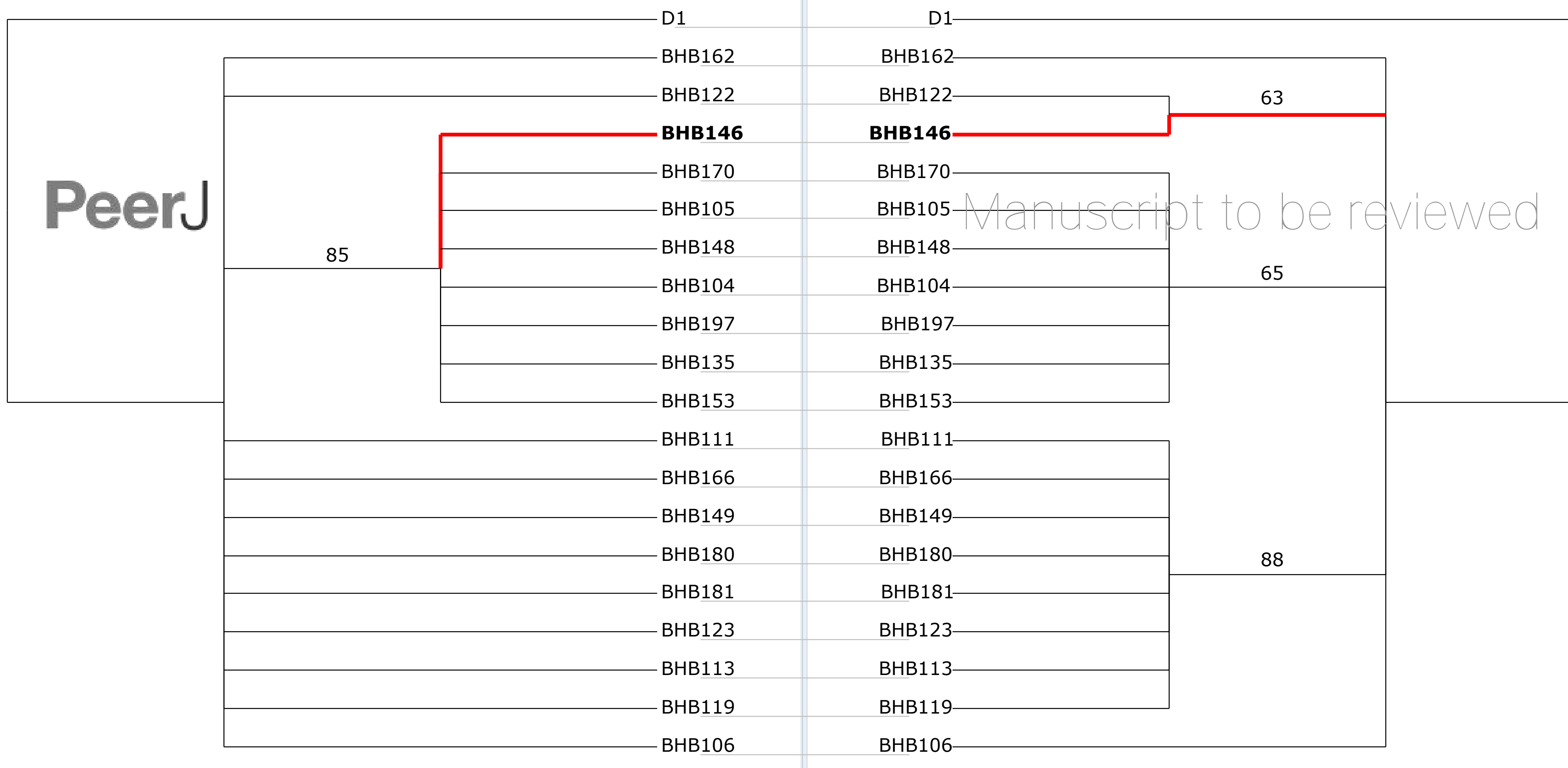

(b)

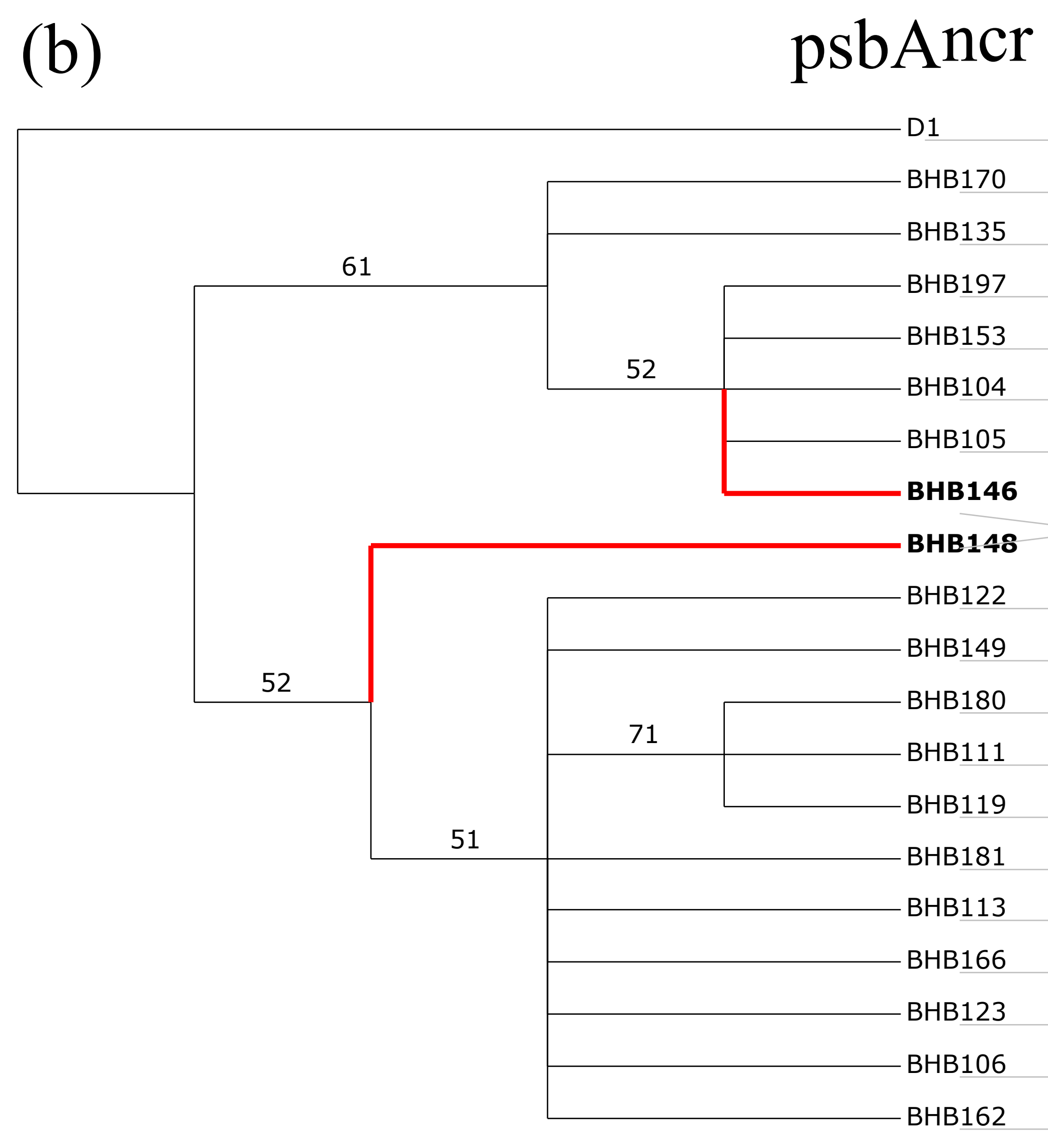

ITS2

\begin{tabular}{|l|}
\hline BHB170- \\
BHB135- \\
BHB197- \\
BHB153- \\
BHB104- \\
BHB105- \\
\hline BHB148- \\
\hline BHB146- \\
BHB122- \\
\hline BHB149- \\
\hline BHB180- \\
BHB111- \\
\hline BHB119- \\
\hline BHB181- \\
\hline BHB113- \\
BHB166- \\
\hline BHB123- \\
BHB106- \\
BHB162- \\
\hline
\end{tabular}

(c)

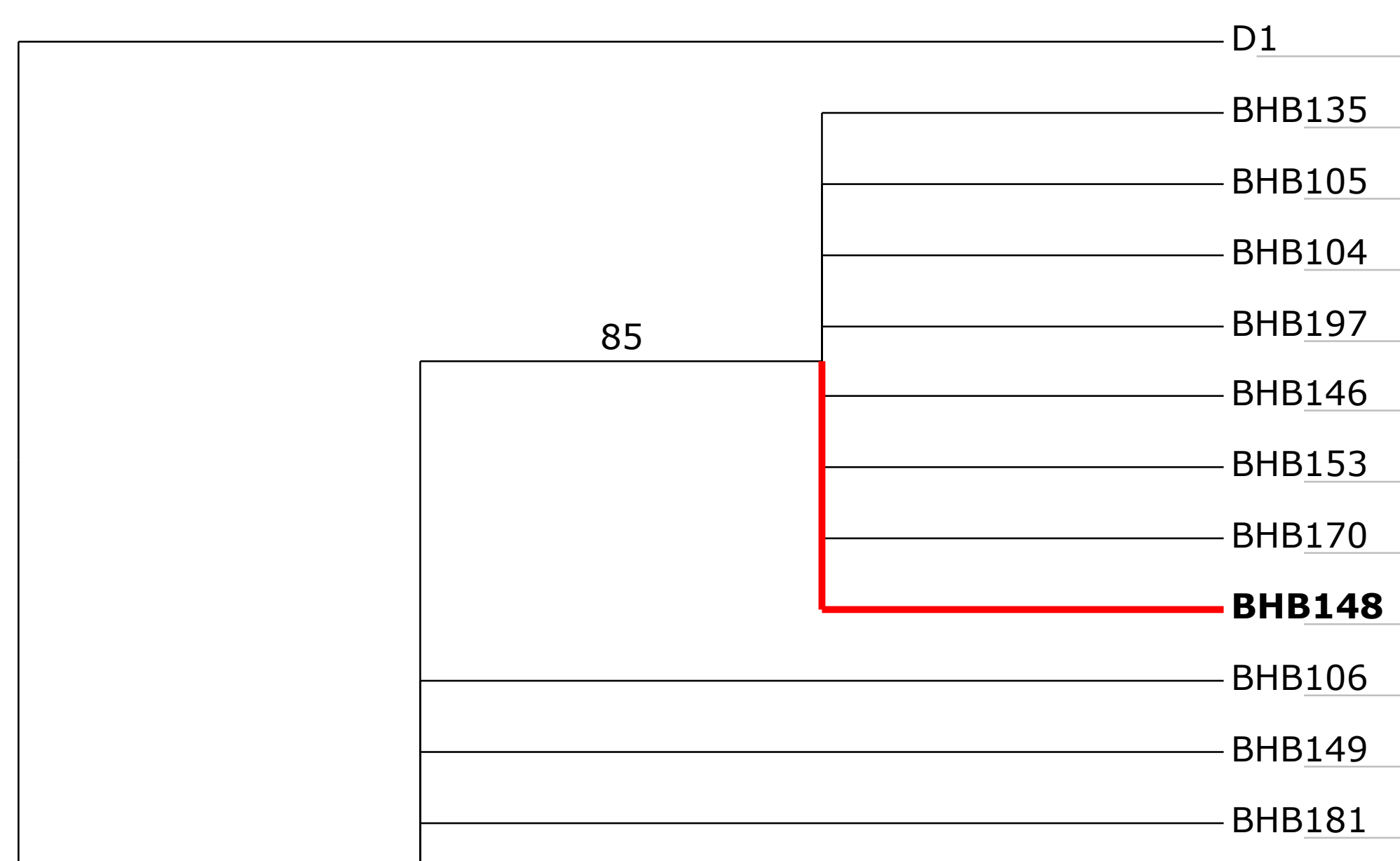

Peer) reviewing PDF | (2019:03:36008:1:1:CHECKBHFM Mbry 2019

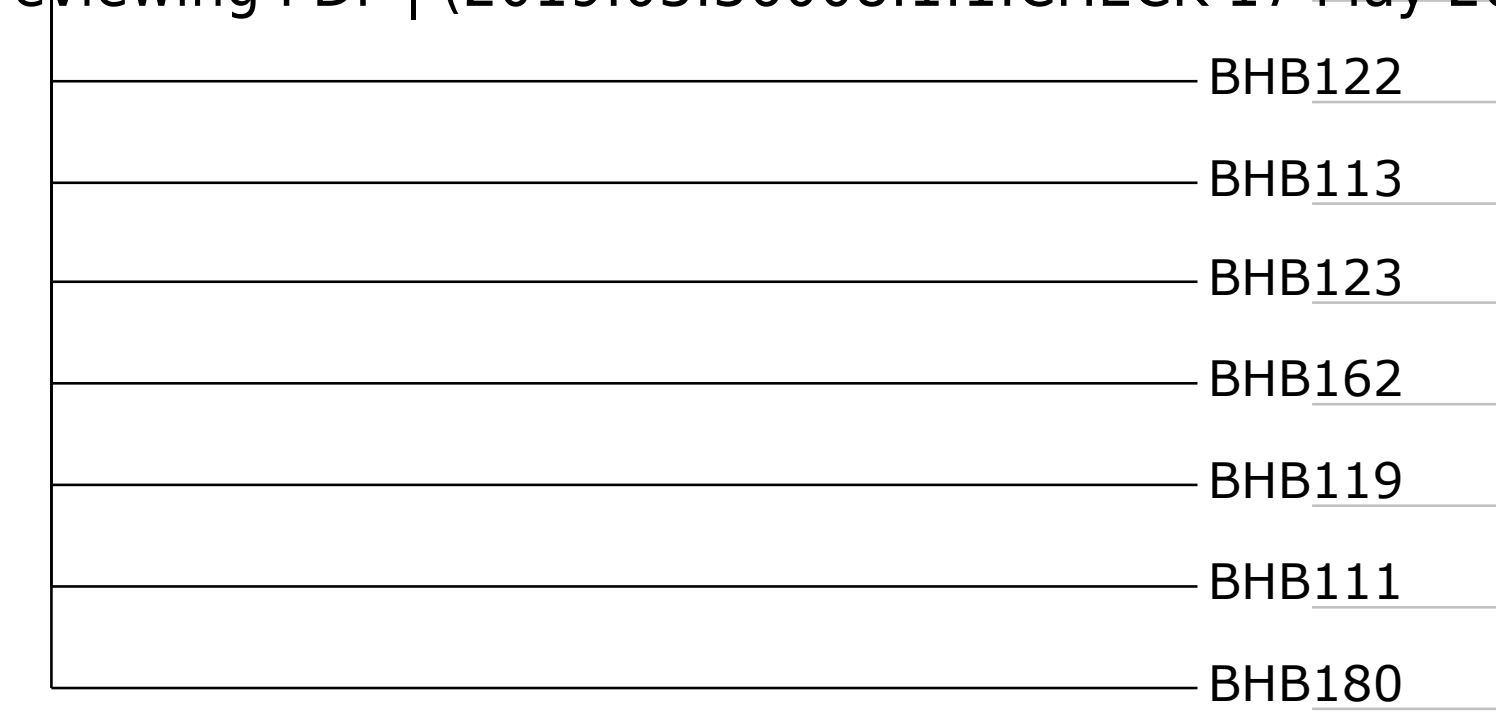

psbAncr

D1

BHB135

BHB105

BHB104

BHB197

BHB146

BHB153

BHB170

BHB148

BHB106

BHB149

BHB181

BHB166

BHB122

BHB113

BHB123

BHB162

BHB119

BHB111

BHB180 
Figure 3 (on next page)

Short selections of raw sequence data for incongruent sample BHB146 and related sequences (polymorphisms in bold).

In organellar gene regions (a) and (c), BHB146 groups with samples BHB104 and BHB105 (Cladocopium type C42a, Clv). In the nuclear gene region (b), BHB groups with BHB122 and BHB149 (Cladocopium type C1\#). 
PeerJ

(a) $c o b$

(b) ITS2

(c) $\mathrm{psbA}^{\mathrm{ncr}}$
BHB104 GGGAGTAC ... TTCTT

BHB105 GGGAGTAC ... TTCTT

BHB122 GGGGGTAC ... TTGTT

BHB146 GGGAGTAC ... TTCTT

BHB149 GGGGGTAC ... TTGTT

\section{$225 \quad 230 \quad 235$}

BHB104 AGG--TTTCTACCTTCGTG

BHB105 AGG--TTTCTACCTTCGTG

BHB122 AAG--TTTCTACCTTCGCG

BHB146 AAG--TTTCTACCTTCGCG BHB149 AAG--TTTCTACCTTCGTG
BHB104 CCCTTCGGG-GTGCACAT BHB105 CCCTTCGGG-GTGCACAT BHB122 CCCGTAGGG-GTACCCAT BHB146 CCCTTCGGG-GTGCACAT Peer) reviewing PDF | (2019:03:36008:1:1:CHECK 17 May 2019)

BHB149 CCCGTAGGG-GTACCCAT 
Figure 4 (on next page)

Pairwise tanglegrams for site BSP.

Red branches with bolded taxa labels indicate incongruent samples, as identified by the tree hybridisation analyses (executed in Dendroscope 3.0 [Huson and Linz 2016]) . Branch labels are ML bootstrap values (1000 replicates for cob, 100 for ITS2 and psbAncr). (a) cob vs. ITS2: found incongruent by ILD and AU tests. (b) psbAncr vs. ITS2: found incongruent by ILD and AU tests. (c) cob vs. psbAncr: found congruent by ILD and AU tests. 
(a)

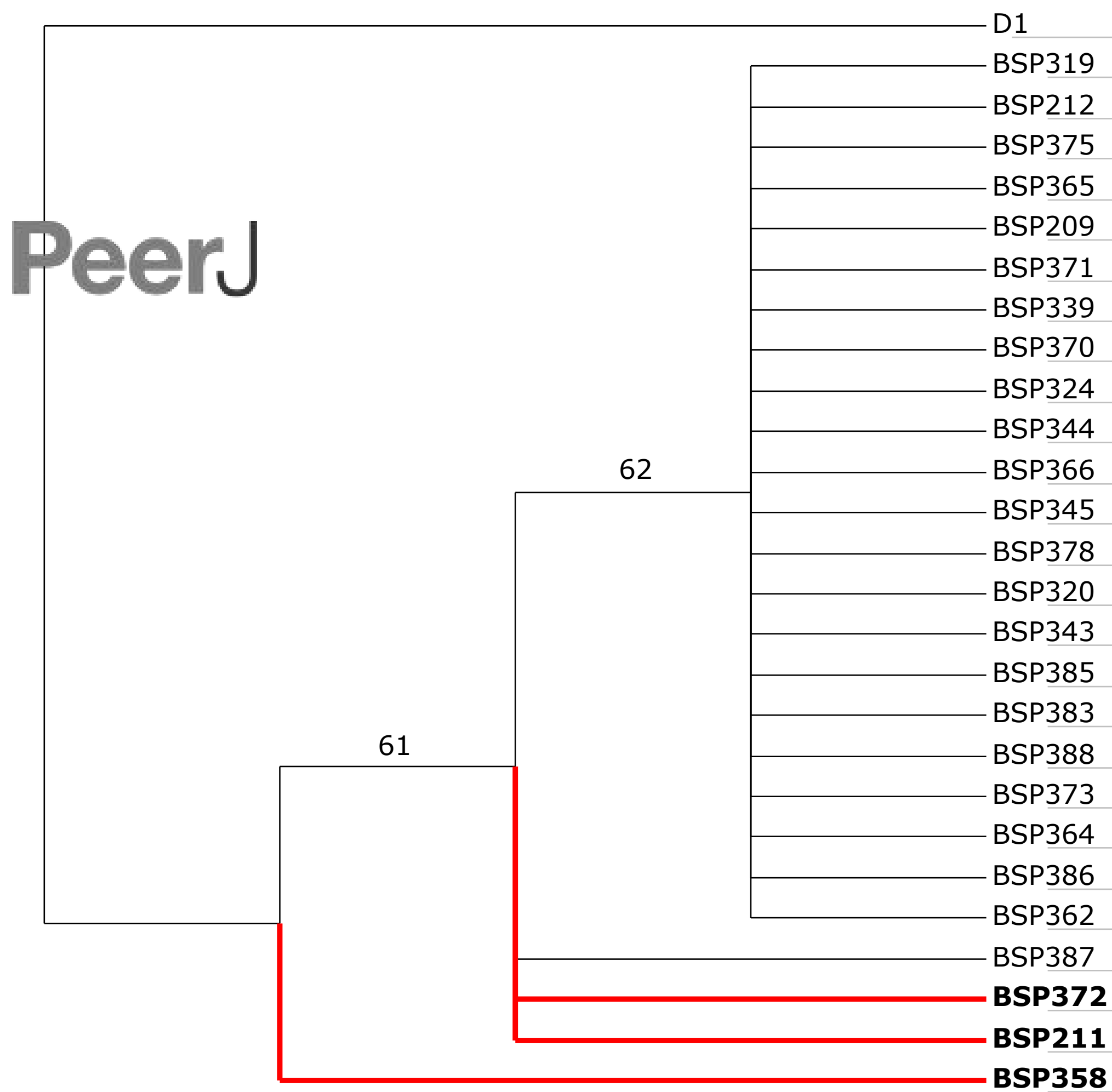

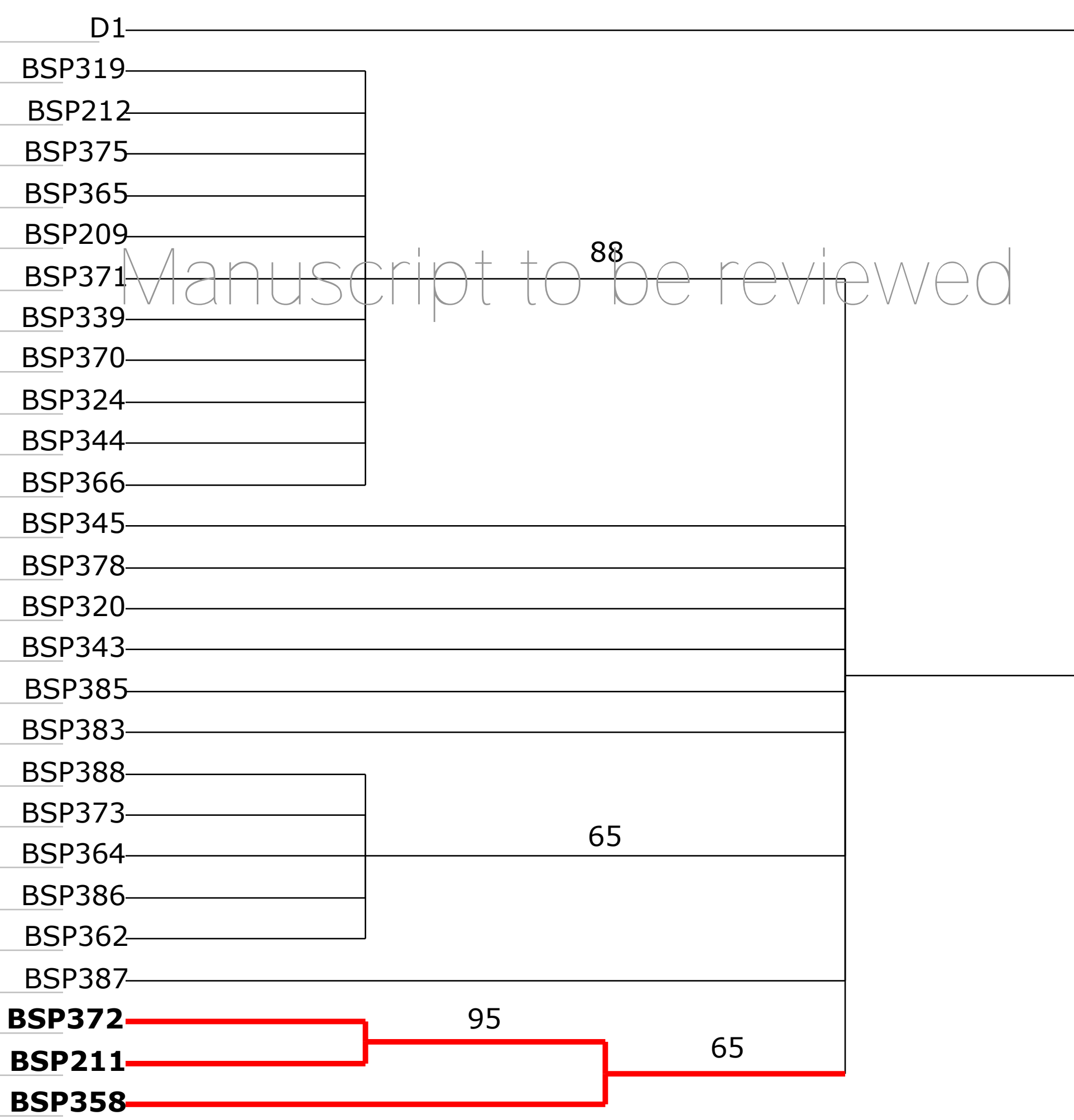

ITS2

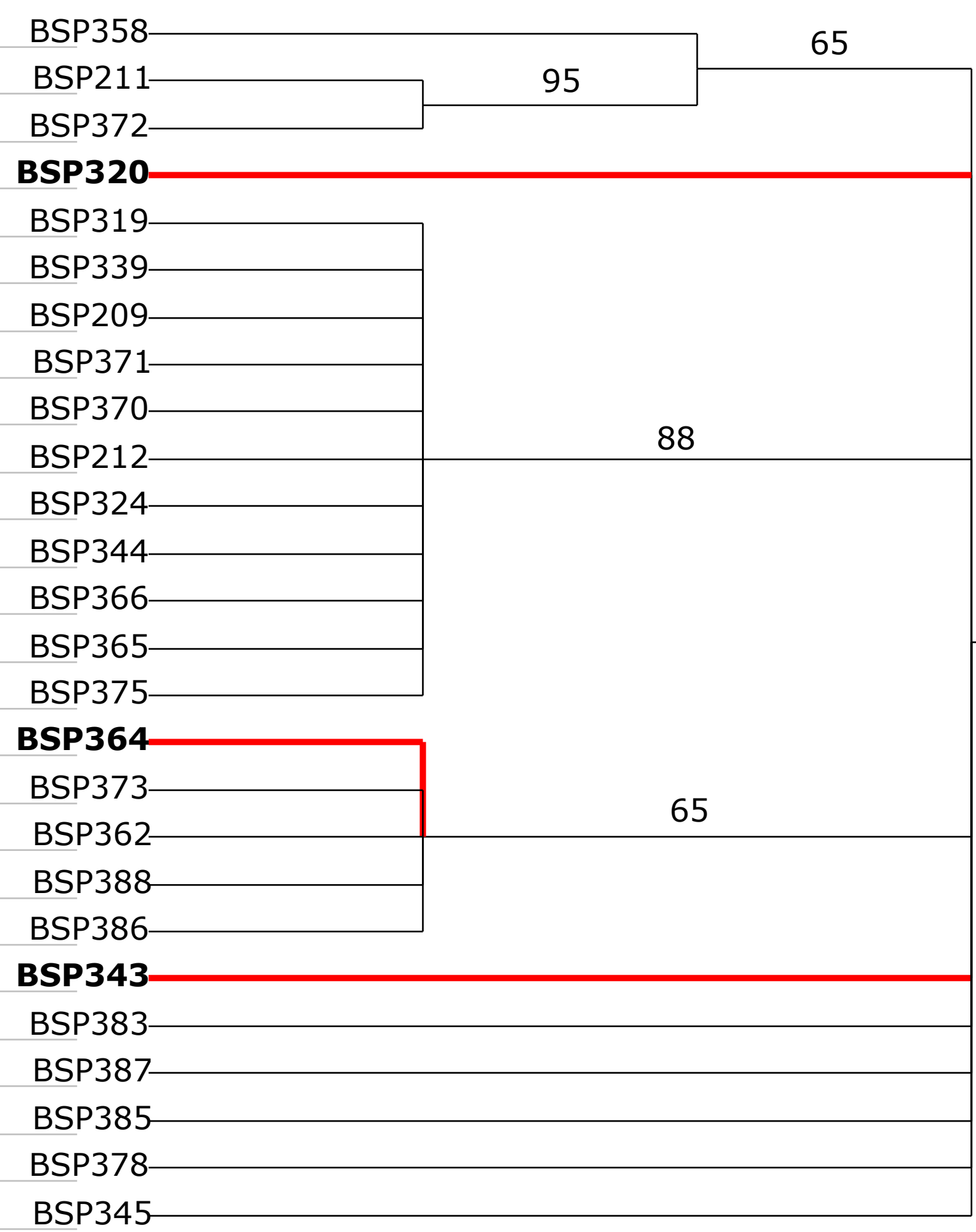

BSP345

$$
\text { D1 }
$$

(c)

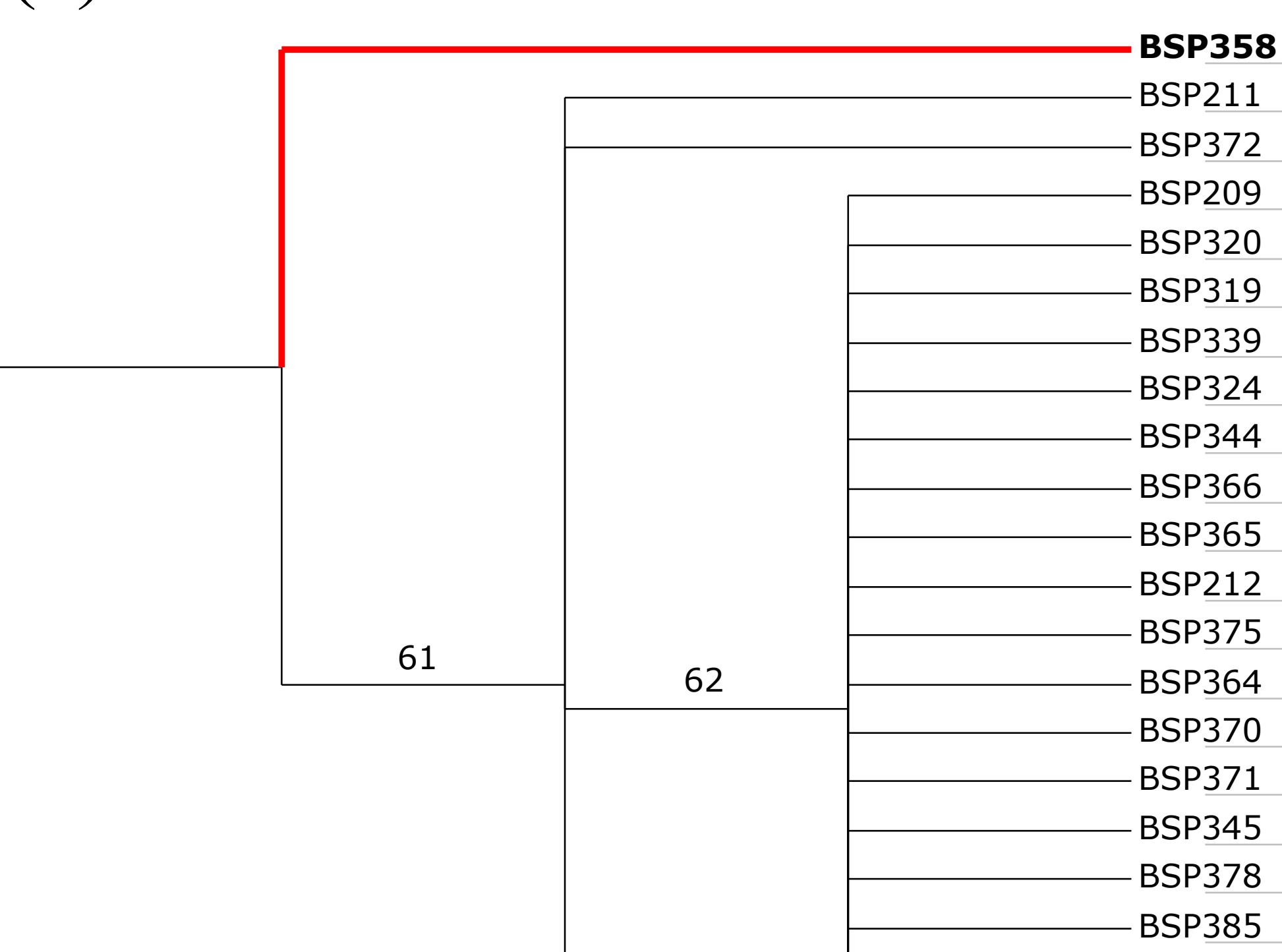

Peer) reviewing PDF | (2019:03:36008:1:1:CHECK 17

BSP358

BSP211

BSP209

BSP319

BSP339

BSP324

BSP344

BSP366

BSP365

BSP212

BSP375

BSP364

BSP370

BSP371

BSP345

BSP378

BSP385

BSP373

BSP362

BSP388

BSP386

BSP343

BSP383

BSP387

\begin{tabular}{l|l}
\hline & 91 \\
&
\end{tabular}

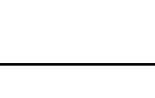

2

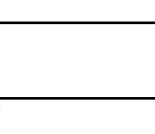

20

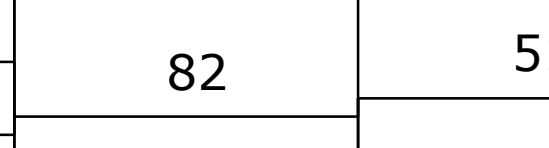

D1

\begin{tabular}{|c|c|c|}
\hline \multirow[b]{2}{*}{63} & 77 & \multirow[b]{2}{*}{66} \\
\hline & & \\
\hline & 66 & \\
\hline
\end{tabular}


Figure $\mathbf{5}$ (on next page)

Short selections of raw sequence data for incongruent sample BSP343 and related sequences (polymorphisms in bold).

(a) In the nuclear ITS2 region, BSP343 groups with samples BSP383 and BSP387; point mutations at base pairs 23 and 238 (available in Data Availability) identify it as Cladocopium type C3u. (b) In the organellar psbAncr region, BSP343 groups with BSP386 and BSP388, as a variant of Cladocopium type C40. The cob gene was invariant in this case. 
(a) ITS2

BSP343 TG-CGCGC CCGCT

BSP383 $\mathrm{TG}-\mathbf{C G C G C}$ BSP386 TG-TGCGC BSP387 TG-CGCGC BSP388 TG-TGCGC

... $\mathrm{CCGCT}$ CTGCT $\mathrm{CCGCT}$ CTGCT

(b) $\mathrm{psbA}^{\mathrm{ncr}}$

BSP343 ATGCC-CCACA-GGGGCAT BSP383 ACACC-CCGGA-GGGGTGT BSP386 ATGCC-CCACA-GGGGCAT BSP387 ACACC-CCGGA-GGGGTGT BSP38 8 A 
Figure 6 (on next page)

Short selections of raw sequence data for incongruent sample BSP364 and related sequences (polymorphisms in bold).

(a) In the nuclear ITS2 region, BSP364 groups with samples BSP362 and BSP373

(Cladocopium type C3z). (b) In the organellar psbA ${ }^{\text {ncr }}$ region, BSP364 groups with BSP344 and BSP366, as a variant of Cladocopium type C40. The cob gene was invariant in this case. 
(a) ITS2

BSP344 TGCTTGCGACCGCTGG

BSP362 TGCTTGCAACTGCTGG

BSP364 TGCTTGCAACTGCTGG

BSP366 TGCTTGCGACCGCTGG

BSP373 TGCTTGCAACTGCTGG

(b) $\mathrm{psbA}^{\mathrm{ncr}}$

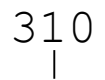

BSP344

BSP362

BSP364

BSP366

BSP373

Manusent 55 be reviewed 60

265 


\section{Figure 7 (on next page)}

Average proportions of different background sequence populations for samples identified as C3z (8 samples) and C40 (13 samples) from site BSP.

(a) For C3z population, proportion of sequences that were C3z vs. non-C3z sequences (i.e. background sequences), averaged over all 8 samples. (b) Average proportion of background sequences for C3z samples, identified using the database of Franklin et al. 2012 and GenBank BLAST search. Sequences followed by stars indicate novel sequences and are named according to their most closely related sequence in the databases. Parentheses indicate the total number of samples (out of 8 ) that the background sequence appeared in. Rare sequences ( $<3 \%$ average individual abundance) are clustered together. The red box indicates the background sequence with the organellar identity of the putative hybrid (BSP364). (c) For C40 population, proportion of sequences that were C40 vs. non-C40 sequences (i.e. background sequences), averaged over all 13 samples. (d) Average proportion of background sequences for $\mathrm{C} 40$ samples. Parentheses indicate the total number of samples (out of 13) that the background sequence appeared in. The red box indicates the background sequence with the nuclear identity of the putative hybrid. Other details as per (b). 
(b) script to be reviewed $\mathrm{C} 40$ (1)

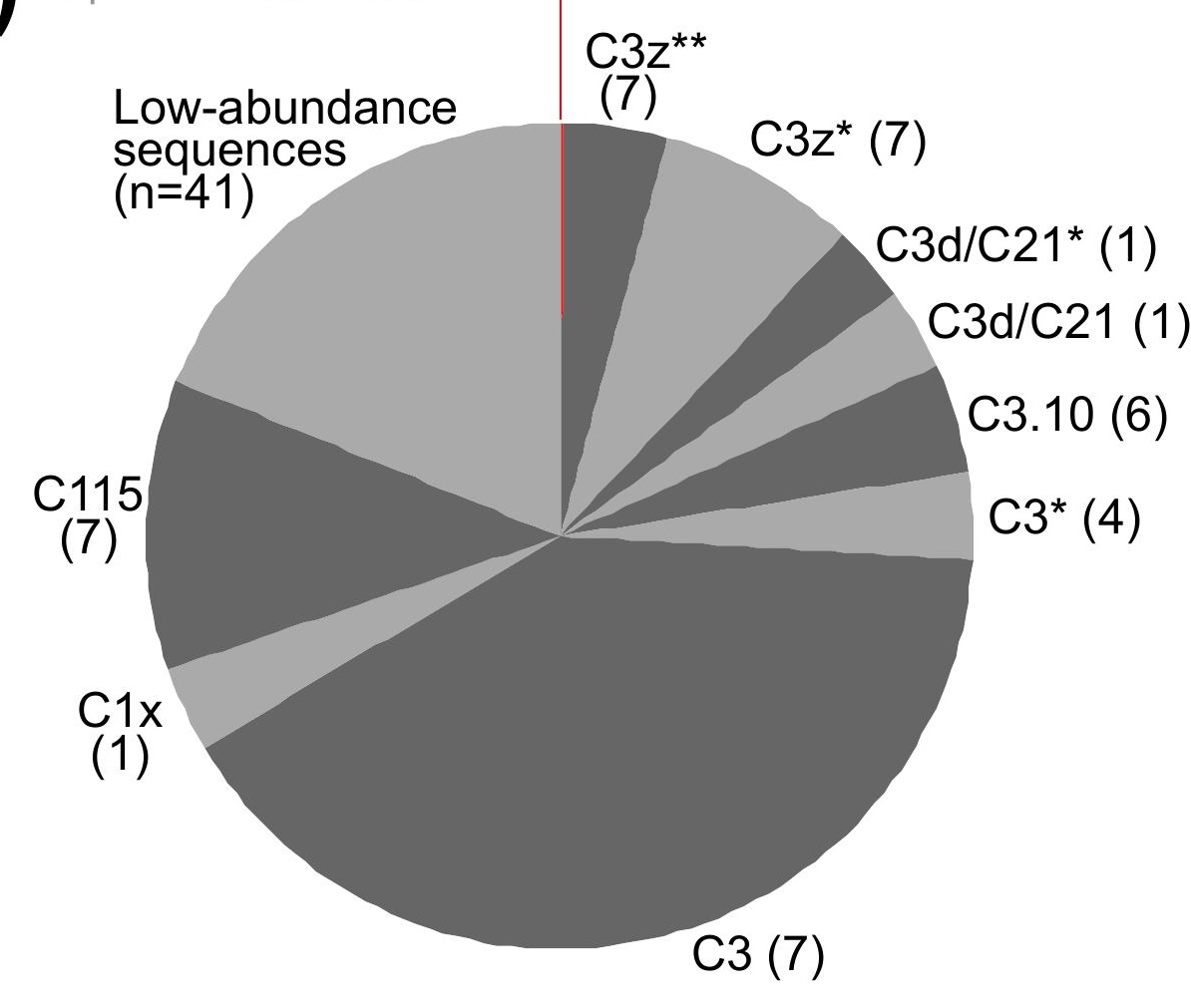

(d)

C3z $(n=8)$

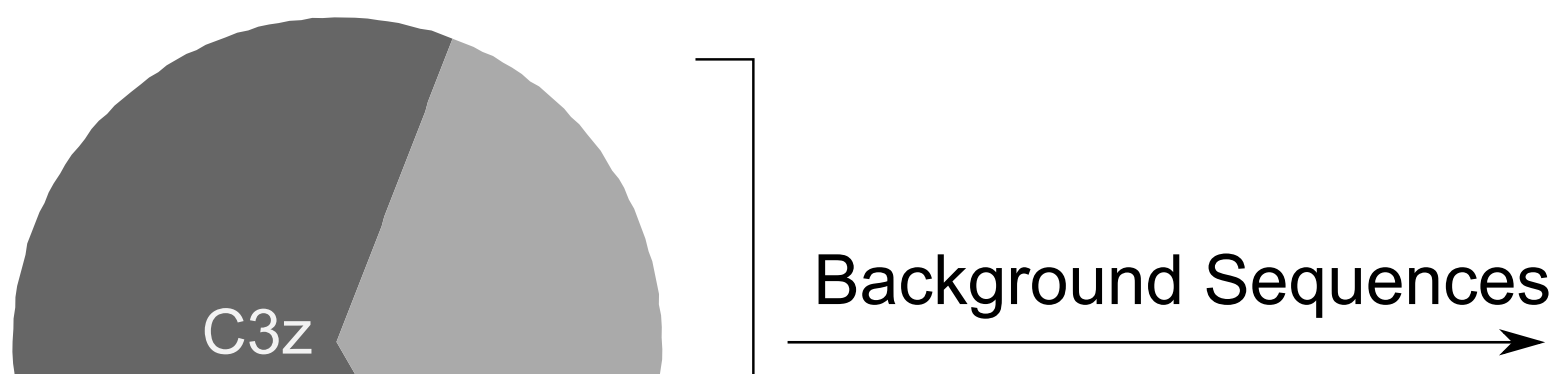

Background Sequences

C40 $(n=13)$

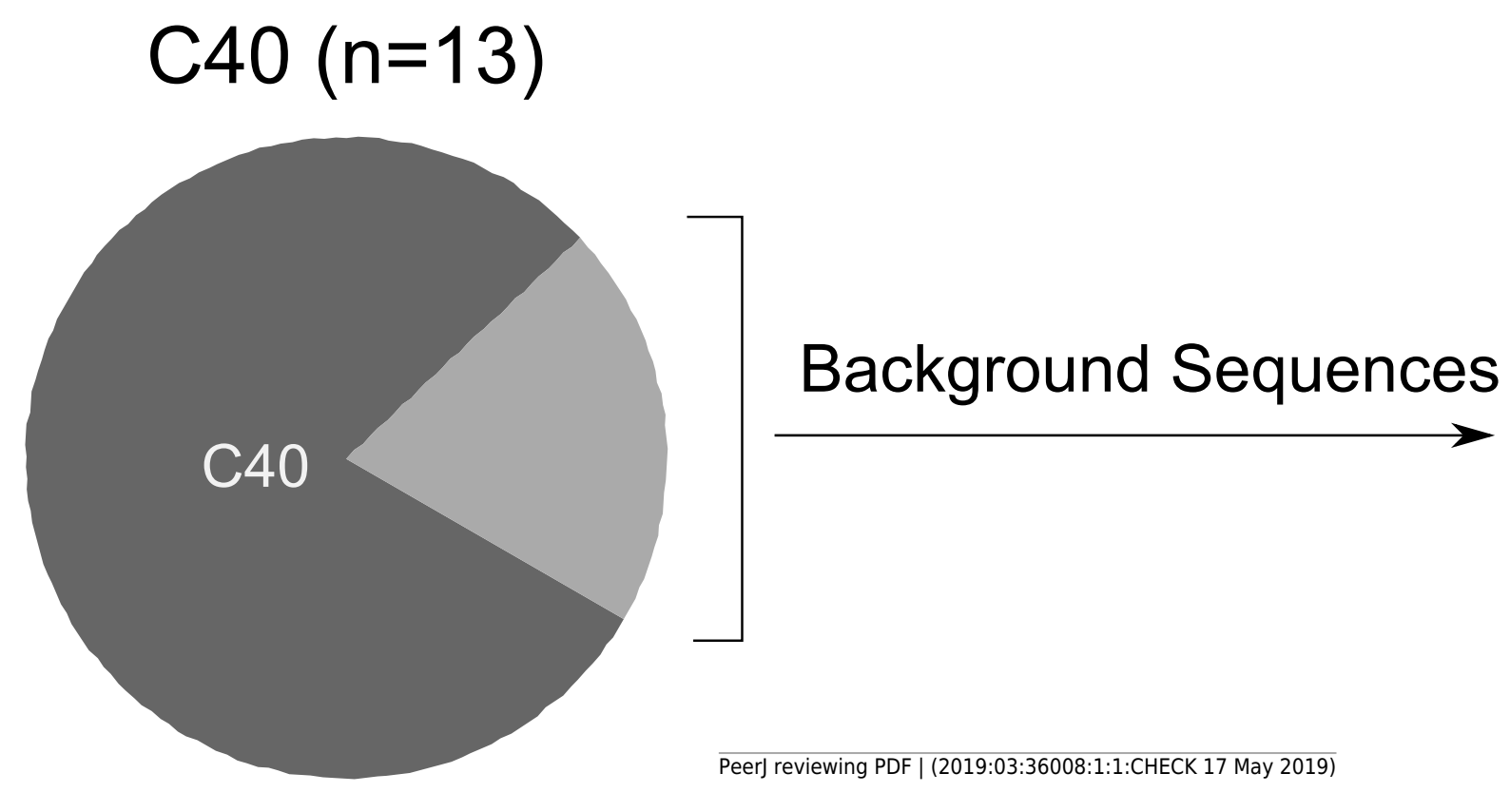

(a)

(c)

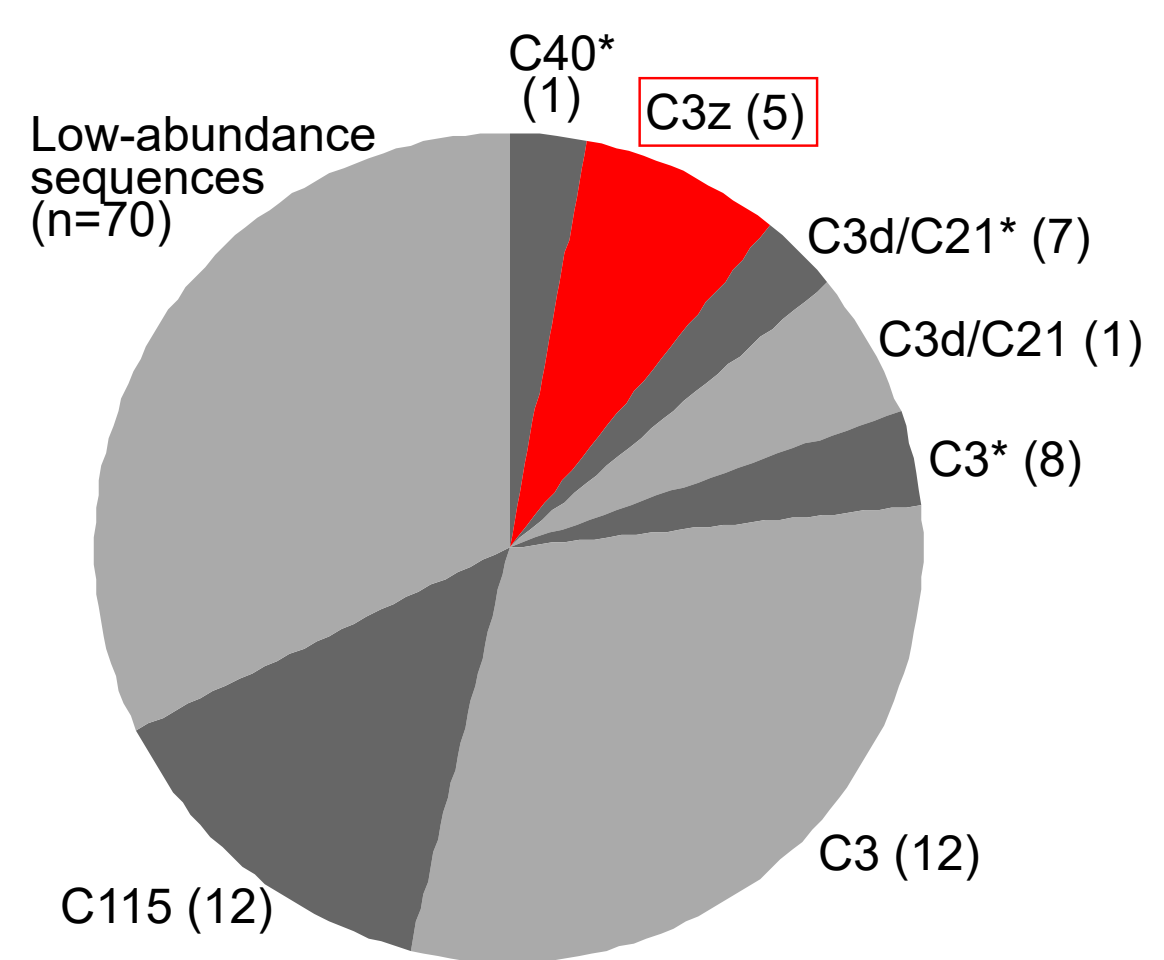




\section{Figure 8 (on next page)}

Predictions under Incomplete Lineage Sorting.

(a) General pattern expected for ILS. A single ancestral population with polymorphism in both the $p s b A^{\text {ncr }}$ and ITS2 regions is present before a speciation event. After speciation, the ITS2 polymorphism fails to segregate, while through stochastic processes the C40 polymorphism is eliminated and leads to incongruence between nuclear and chloroplast genes. (b) The process of ILS that would be required for this example. The ITS2 region fails to segregate after speciation; despite the extensive presence of $\mathrm{C} 40$ alleles, a small subpopulation of symbionts with dominant C $3 z$ alleles is maintained (weak dashed blue line) in the C40 population and both are recovered in present-day sampling, at the same site, as pure C3z populations. 


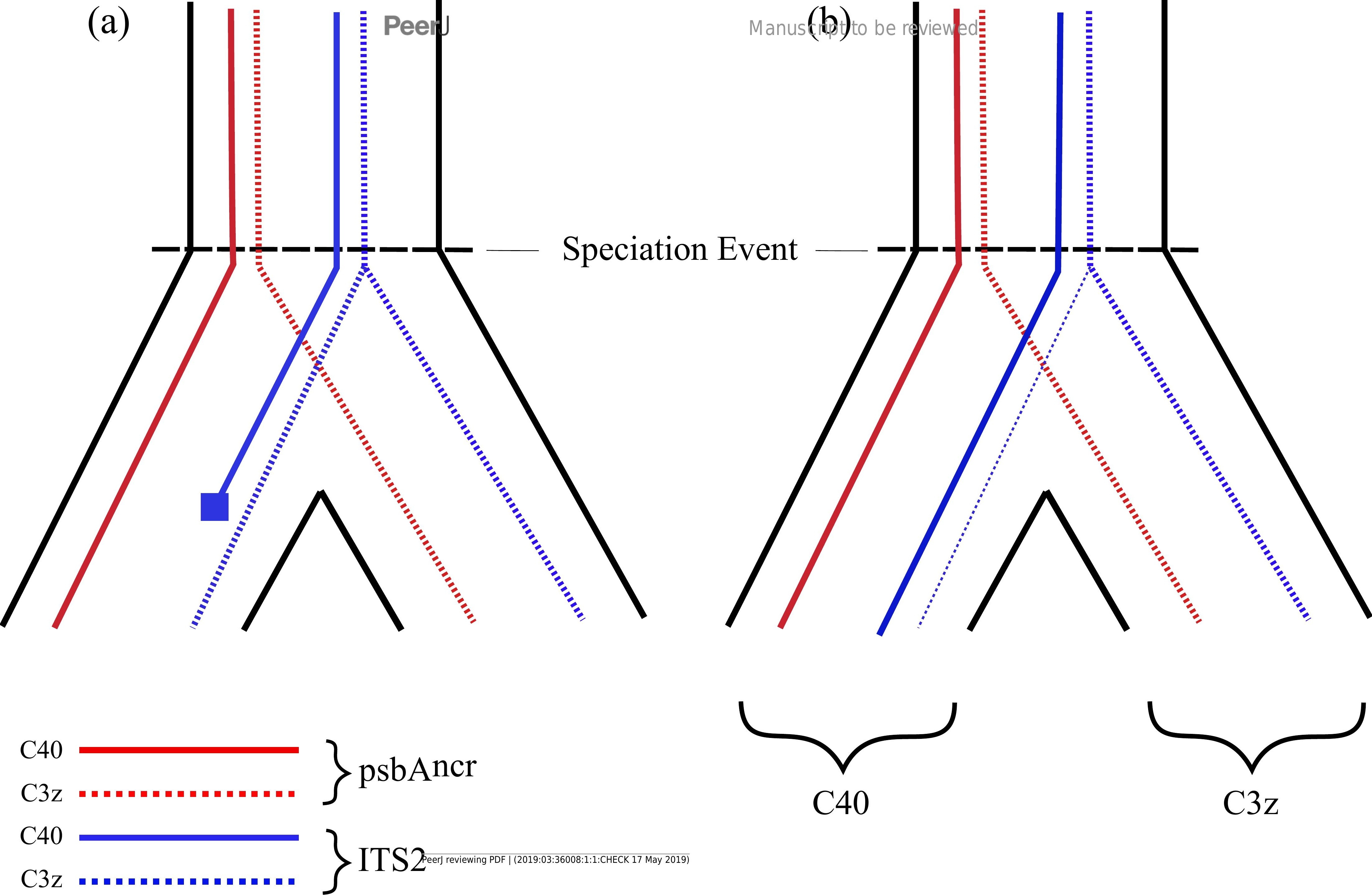




\section{Table $\mathbf{1}$ (on next page)}

Results of the Approximately Unbiased (AU) tests.

P-values presented are whether a candidate tree is statistically differentiable from the best tree. Statistical significance is designated by * (conclusions drawn at Bonferroni-corrected $\alpha$ $=0.0085) ; p$-values likely due to type I error are designated by $\cong$ (see Discussion). 
1 Table 1: Results of the Approximately Unbiased (AU) tests. P-values presented are whether a 2 candidate tree is statistically differentiable from the best tree. Statistical significance is designated 3 by * (conclusions drawn at Bonferroni-corrected $\alpha=0.0085$ ); p-values likely due to type I error 4 are designated by ${ }^{\circ}$ (see Discussion).

\begin{tabular}{|c|c|c|c|c|}
\hline Dataset & $\begin{array}{l}\text { Gene region } \\
\text { used for test }\end{array}$ & Best tree & $\begin{array}{l}\text { Tree to compare } \\
\text { with best tree }\end{array}$ & AU p-value \\
\hline \multirow[t]{6}{*}{ BBR } & \multirow[t]{2}{*}{$c o b$} & \multirow[t]{2}{*}{$\mathrm{psbA}^{\text {ncr }}$} & ITS2 & $<0.0001^{\circ}$ \\
\hline & & & $c o b$ & 0.4417 \\
\hline & \multirow[t]{2}{*}{ ITS2 } & \multirow[t]{2}{*}{ ITS2 } & $c o b$ & 0.4056 \\
\hline & & & $\mathrm{psbA}^{\text {ncr }}$ & 0.7712 \\
\hline & \multirow[t]{2}{*}{$\mathrm{psbA}^{\mathrm{ncr}}$} & \multirow[t]{2}{*}{$\mathrm{psbA}^{\mathrm{ncr}}$} & $c o b$ & $<0.0001^{\circ}$ \\
\hline & & & ITS2 & $<0.0001^{\circ}$ \\
\hline \multirow[t]{6}{*}{$\mathrm{BHB}$} & \multirow[t]{2}{*}{$c o b$} & \multirow[t]{2}{*}{$c o b$} & ITS2 & $<0.0001^{*}$ \\
\hline & & & $\mathrm{psbA}^{\mathrm{ncr}}$ & 0.5631 \\
\hline & \multirow[t]{2}{*}{ ITS2 } & \multirow[t]{2}{*}{ ITS2 } & $c o b$ & $<0.0001^{*}$ \\
\hline & & & $\mathrm{psbA}^{\text {ncr }}$ & $<0.0001^{*}$ \\
\hline & \multirow[t]{2}{*}{$\mathrm{psbA}^{\text {ncr }}$} & \multirow[t]{2}{*}{$\mathrm{psbA}^{\mathrm{ncr}}$} & $c o b$ & $<0.0001^{\mathrm{o}}$ \\
\hline & & & ITS2 & $<0.0001^{\circ}$ \\
\hline \multirow[t]{6}{*}{ BLS } & \multirow[t]{2}{*}{$c o b$} & \multirow[t]{2}{*}{$c o b$} & ITS2 & $<0.0001^{*}$ \\
\hline & & & $\mathrm{psbA}^{\mathrm{ncr}}$ & 0.3456 \\
\hline & \multirow[t]{2}{*}{ ITS2 } & \multirow[t]{2}{*}{ ITS2 } & $c o b$ & 0.4163 \\
\hline & & & $\mathrm{psbA}^{\text {ncr }}$ & 0.1806 \\
\hline & \multirow[t]{2}{*}{$\mathrm{psbA}^{\mathrm{ncr}}$} & \multirow[t]{2}{*}{$\mathrm{psbA}^{\mathrm{ncr}}$} & $c o b$ & $<0.0001^{\mathrm{o}}$ \\
\hline & & & ITS2 & $<0.0001^{\circ}$ \\
\hline \multirow[t]{6}{*}{$\mathrm{BSP}$} & \multirow[t]{2}{*}{$c o b$} & \multirow[t]{2}{*}{$c o b$} & ITS2 & 0.0493 \\
\hline & & & $\mathrm{psbA}^{\mathrm{ncr}}$ & $<0.0001^{*}$ \\
\hline & \multirow[t]{2}{*}{ ITS2 } & ITS2 & $c o b$ & $<0.0001^{*}$ \\
\hline & & & $\mathrm{psbA}^{\text {ncr }}$ & $<0.0001^{*}$ \\
\hline & $\mathrm{psbA}^{\mathrm{ncr}}$ & $\mathrm{psbA}^{\text {ncr }}$ & $c o b$ & $<0.0001^{\circ}$ \\
\hline & & & ITS2 & $<0.0001^{\circ}$ \\
\hline HEW & $c o b$ & $\mathrm{psbA}^{\text {ncr }}$ & ITS2 & 0.1562 \\
\hline & & & $\mathrm{psbA}^{\text {ncr }}$ & 0.1562 \\
\hline & ITS2 & ITS2 & $c o b$ & 0.5465 \\
\hline & & & $\mathrm{psbA}^{\text {ncr }}$ & 0.5465 \\
\hline & $\mathrm{psbA}^{\mathrm{ncr}}$ & $\mathrm{psbA}^{\text {ncr }}$ & $c o b$ & $<0.0001^{\circ}$ \\
\hline & & & ITS2 & $<0.0001^{\circ}$ \\
\hline LIE & $c o b$ & ITS2 & $c o b$ & 0.0183 \\
\hline & & & $\mathrm{psbA}^{\text {ncr }}$ & 0.2336 \\
\hline & ITS2 & ITS2 & $c o b$ & 0.0870 \\
\hline & & & $\mathrm{psbA}^{\text {ncr }}$ & 0.4727 \\
\hline & $\mathrm{psbA}^{\mathrm{ncr}}$ & $\mathrm{psbA}^{\text {ncr }}$ & $c o b$ & $<0.0001^{\circ}$ \\
\hline & & & ITS2 & $<0.0001^{\circ}$ \\
\hline LIW & $c o b$ & $c o b$ & ITS2 & 0.0409 \\
\hline & & & psbA $^{\text {ncr }}$ & 0.0811 \\
\hline & ITS2 & ITS2 & $c o b$ & 0.2490 \\
\hline & & & $\mathrm{psbA}^{\text {ncr }}$ & 0.6638 \\
\hline & $\mathrm{psbA}^{\mathrm{ncr}}$ & $\mathrm{psbA}^{\text {ncr }}$ & $c o b$ & $<0.0001^{\circ}$ \\
\hline & & & ITS2 & $<0.0001^{\circ}$ \\
\hline
\end{tabular}




\begin{tabular}{|c|c|c|c|c|}
\hline \multirow[t]{6}{*}{ Atauro } & \multirow[t]{2}{*}{$c o b$} & \multirow[t]{2}{*}{$c o b$} & ITS2 & $<0.0001^{*}$ \\
\hline & & & $\mathrm{psbA}^{\mathrm{ncr}}$ & 0.0125 \\
\hline & \multirow[t]{2}{*}{ ITS2 } & \multirow[t]{2}{*}{ ITS2 } & $c o b$ & $<0.0001^{*}$ \\
\hline & & & $\mathrm{psbA}^{\text {ncr }}$ & $<0.0001^{*}$ \\
\hline & \multirow[t]{2}{*}{$\mathrm{psbA}^{\mathrm{ncr}}$} & \multirow[t]{2}{*}{$\mathrm{psbA}^{\text {ncr }}$} & $c o b$ & $<0.0001^{\circ}$ \\
\hline & & & ITS2 & $<0.0001^{\circ}$ \\
\hline \multirow[t]{6}{*}{ Timor } & \multirow[t]{2}{*}{$c o b$} & \multirow[t]{2}{*}{$c o b$} & ITS2 & 0.5604 \\
\hline & & & psbA $^{\text {ncr }}$ & 0.0196 \\
\hline & \multirow[t]{2}{*}{ ITS2 } & \multirow[t]{2}{*}{ ITS2 } & $c o b$ & $<0.0001 *$ \\
\hline & & & $\mathrm{psbA}^{\mathrm{ncr}}$ & 0.0935 \\
\hline & \multirow[t]{2}{*}{$\mathrm{psbA}^{\mathrm{ncr}}$} & \multirow[t]{2}{*}{$\mathrm{psbA}$} & $c o b$ & $<0.0001^{\circ}$ \\
\hline & & & ITS2 & $<0.0001^{\circ}$ \\
\hline
\end{tabular}

5 


\section{Table 2 (on next page)}

Results of pairwise Incongruence Length Difference tests.

Conclusions were drawn at a Bonferroni-corrected $\alpha=0.017$. Statistical significance is designated by *. 
1 Table 2: Results of pairwise Incongruence Length Difference tests. Conclusions were drawn at a

2 Bonferroni-corrected $\alpha=0.017$. Statistical significance is designated by $*$.

\begin{tabular}{|c|c|c|}
\hline Dataset & Partitions tested & p-value \\
\hline \multirow[t]{3}{*}{ BHB } & $c o b$ vs. ITS2 & $0.006^{*}$ \\
\hline & $c o b$ vs. psbA ${ }^{\mathrm{ncr}}$ & 0.847 \\
\hline & ITS2 vs. psbA ncr $^{\text {na }}$ & 0.021 \\
\hline \multirow[t]{3}{*}{$\mathrm{BSP}$} & $c o b$ vs. ITS2 & $0.011^{*}$ \\
\hline & $c o b$ vs. psbA ${ }^{\text {ncr }}$ & 0.223 \\
\hline & ITS2 vs. psbA ncr $^{\text {nat }}$ & $0.001 *$ \\
\hline \multirow[t]{3}{*}{ Atauro } & $c o b$ vs. ITS2 & $0.01 *$ \\
\hline & $c o b$ vs. psbA ${ }^{\text {ncr }}$ & 1 \\
\hline & ITS2 vs. psbA ${ }^{\text {ncr }}$ & $0.01 *$ \\
\hline \multirow[t]{3}{*}{ BLS } & $c o b$ vs. ITS2 & 1 \\
\hline & $c o b$ vs. psbA $\mathrm{A}^{\text {ncr }}$ & 1 \\
\hline & ITS2 vs. psbA ncr & 0.778 \\
\hline \multirow[t]{3}{*}{ LIW } & $c o b$ vs. ITS2 & 1 \\
\hline & $c o b$ vs. psbA ncr & 1 \\
\hline & ITS2 vs. psbA ${ }^{\text {ncr }}$ & 1 \\
\hline
\end{tabular}

3 


\section{Table 3(on next page)}

Summary of incongruent samples inferred from tanglegrams and tree hybridisation analyses.

Bolded samples are those verified to be incongruent. 
1 Table 3: Summary of incongruent samples inferred from tanglegrams and tree hybridisation

2 analyses. Bolded samples are those verified to be incongruent.

\begin{tabular}{|c|c|c|}
\hline Dataset & Comparison & Incongruent Samples \\
\hline \multirow[t]{3}{*}{ BHB } & cobvs. ITS2 & BHB146 \\
\hline & $\mathrm{psbA}^{\mathrm{ncr}} v s$. ITS2 & BHB146, BHB148 \\
\hline & cobvs. psbA ncr & BHB148 \\
\hline \multirow[t]{3}{*}{$\mathrm{BSP}$} & cobvs. ITS2 & BSP211, BSP358, BSP372 \\
\hline & $\mathrm{psbA}^{\mathrm{ncr}} v s$. ITS2 & BSP320, BSP343, BSP364 \\
\hline & cobvs. psbA ${ }^{\text {ncr }}$ & BSP358 \\
\hline \multirow[t]{3}{*}{ Atauro } & cobvs. ITS2 & BHB146, BSP372, BSP387 \\
\hline & $\mathrm{psbA}^{\mathrm{ncr}} v s$. ITS2 & BHB146, BHB148, BSP343, BSP364, BSP372 \\
\hline & $\operatorname{cob} v s . \mathrm{psbA}^{\mathrm{ncr}}$ & BHB148, BSP372, BSP387 \\
\hline
\end{tabular}

3 